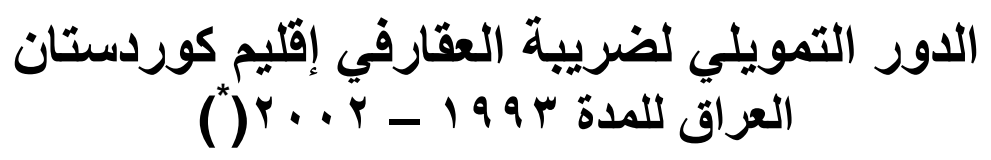

\author{
الاكتور امين محمد سعيد الادريسي \\ الإنتاذ مساعد- قسم الاقتصناد الإدين \\ كلية الإدارة و الاقتصاد- جامعة صلاح الدين \\ اربيل \\ ameenalidressi@maktoob.com
}

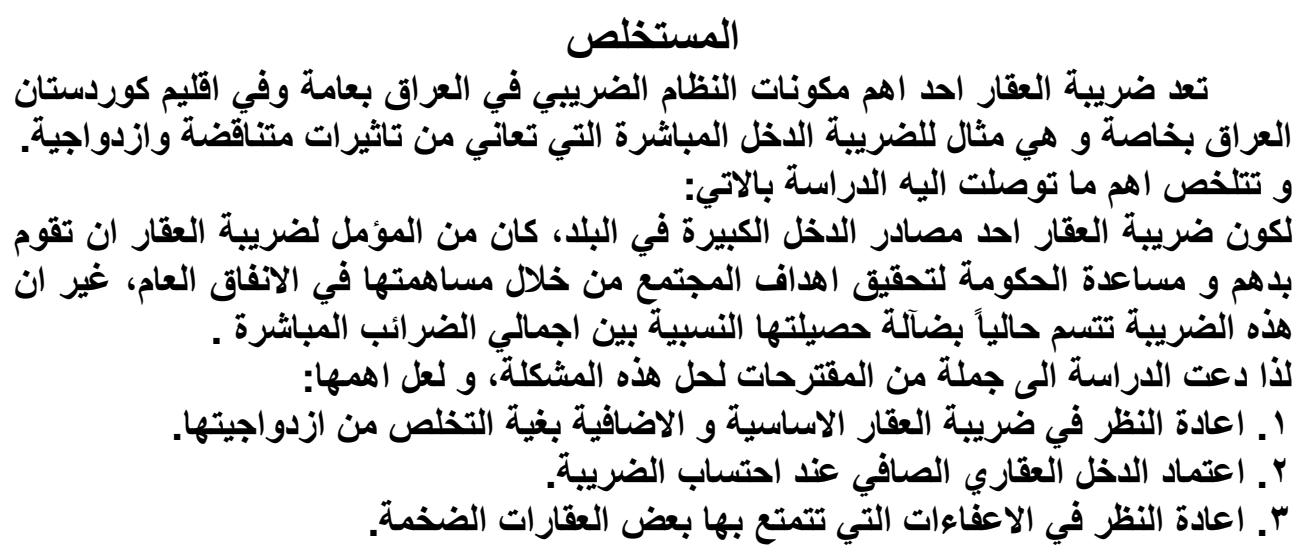

\title{
The Funding Role Of Estate Tax In The Iraqi \\ Kurdistan Region For The Period 1993 - 2002
}

\author{
Ameen M. S. ALidresi (PhD) \\ Assist. Pr. Economic Dept. \\ College of Admin.\&Economics \\ Salahaddin Uni. Erbil
}

Mohamed S. Mohamed Lecturer

College of Admin.\&Economics

Salahaddin Uni. Erbil

\begin{abstract}
Estate ( Built ) tax is considered as one of the important constituents of tax system in Iraq and especially in the Iraqi Kurdistan region. It is a typical direct income tax which is also dual and it has contradictory and bilateral effects.

$$
\begin{aligned}
& \text { (") بحث مستل من اطروحة دكتوراة بعنوان (ضريبة العقار ودور ها في تمويل الموازنة العامة في }
\end{aligned}
$$

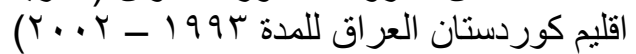

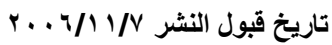

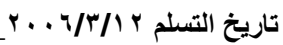


The important summary of the research is :

Being one of the sources of mass income of a country, estate tax attempts to reinforce and support the government through achieving the aims of society. This is done through the general expenditure of this tax which contributes, in a limited degree, to cover the financial and the funds aspects.

There are many important suggestions to solve the above mentioned broblem such as :

1. Getting review of bilateral effects of built tax (The basic and additional ).

2. Imposing the built tax on the net income as a base of the tax .

3. Revise the exemptions of this tax base, especially some big buildings which discluded .

$$
\begin{aligned}
& \text { لضريبة العقار أهمية خاصة في إقليم كوردستان العراق، لانها تسهم بجزء الإنهاء }
\end{aligned}
$$

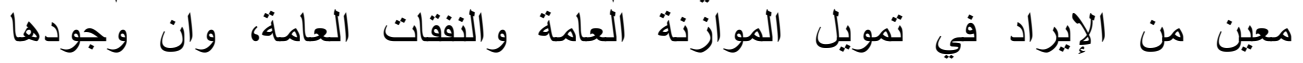

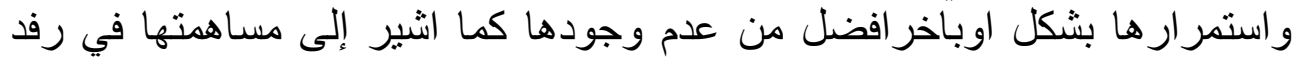

$$
\begin{aligned}
& \text { الخز انة للقيام بالانفاق . }
\end{aligned}
$$

تنبع أهمية هذه الدراسة من أنها تعمل على تشخيص دورضية الدهريبة العقار في

$$
\text { أهمية الاراسة }
$$

تمويل الموازنة العامة لحكومة الإقليم، وتثخيص هذا الدور سيساعد بالتأكيد صاحب التهب

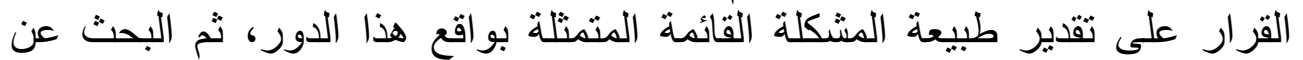
الحلول التي من شأنها تطوير الدور التمويلي لضرئية الترية العقار .

مشكلة الدراسة

تتجسد مشكلة الدراسة بالتعرف على التى حجم مساهمة ضريبة العقار في الدور

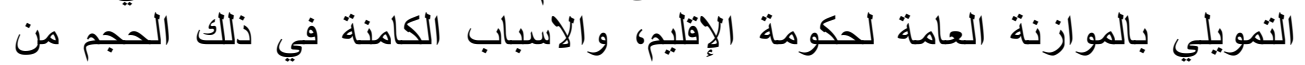

\section{فرضية الاراسة}

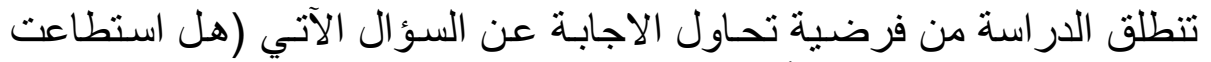

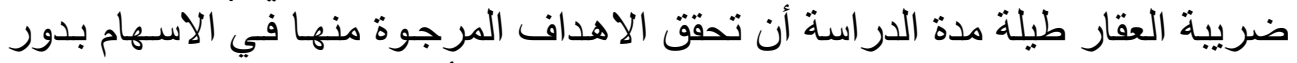

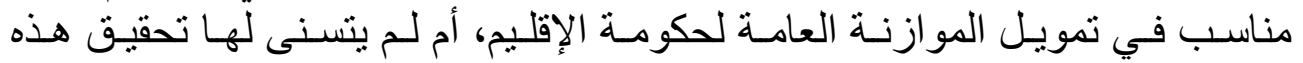

$$
\text { هدف الدراسة }
$$

تهدف الدراسة إلى تحديد مدى مساهمة الضريبة العقارية في الحصيلة

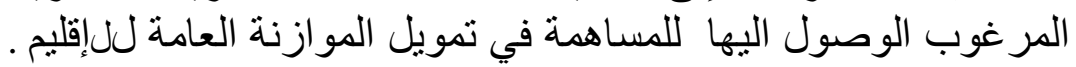




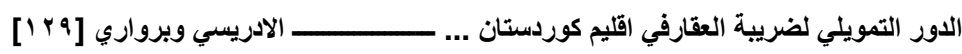

تعتمد الدراسة الاسلوب الاستقرائي التحليلي، بالاعتماد على بيانات حصيلة

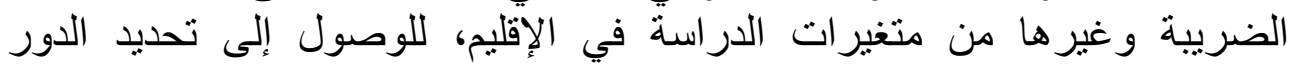

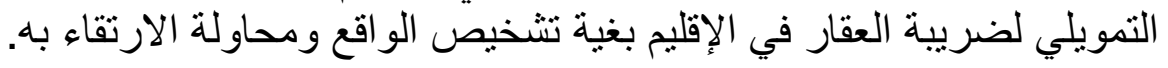

$$
\begin{aligned}
& \text { حدود الاراسة }
\end{aligned}
$$

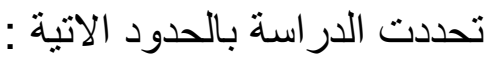

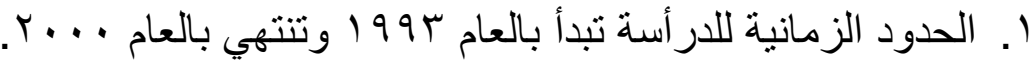

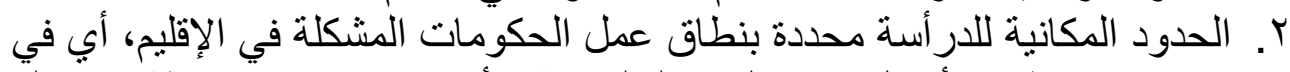

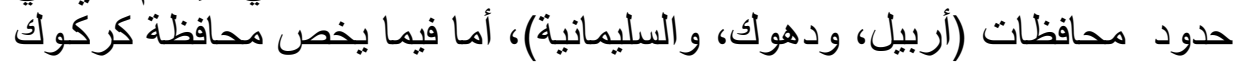

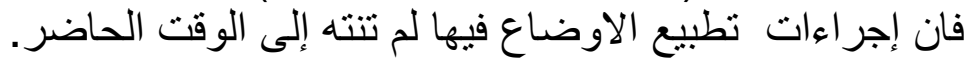

المدخل

الموازنـة العامة بالإقليم

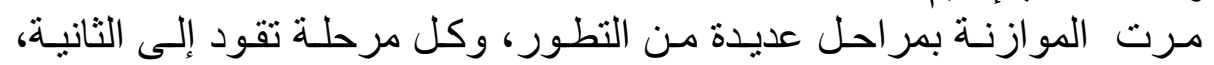

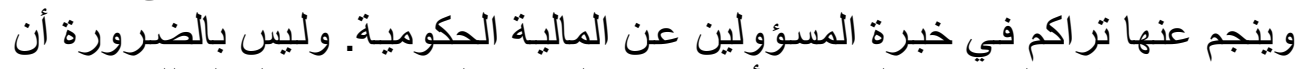

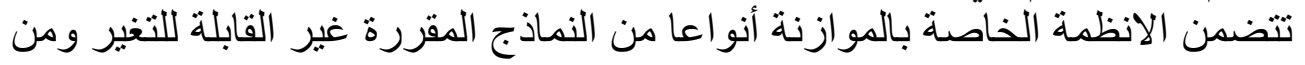

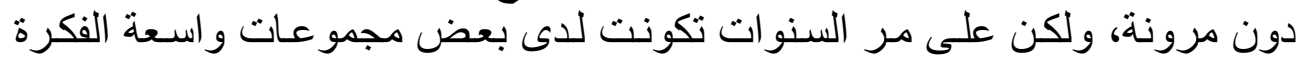

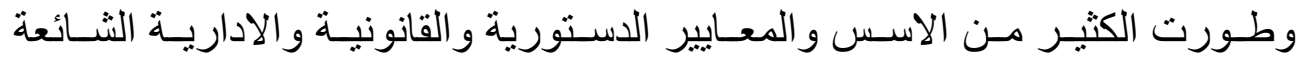

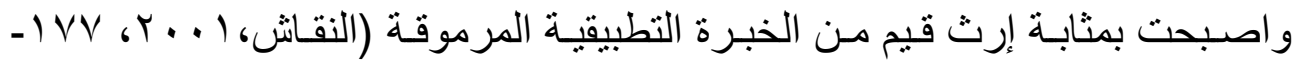

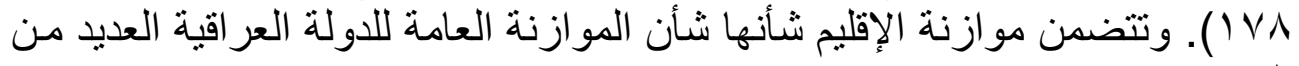

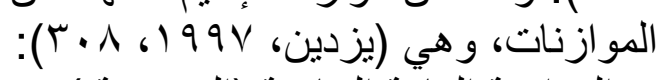

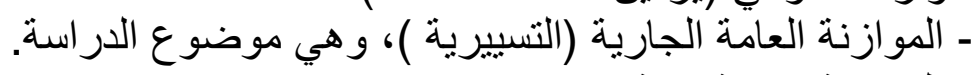
- الموازنة الاستثمارية.

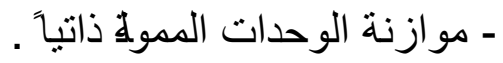

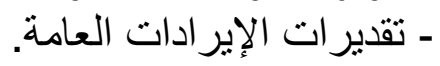

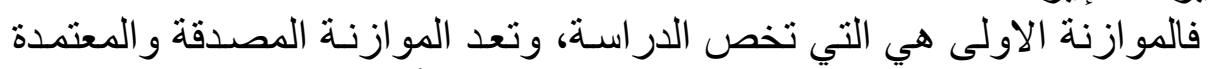

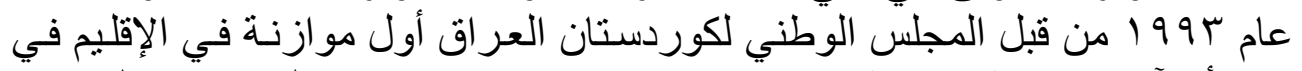

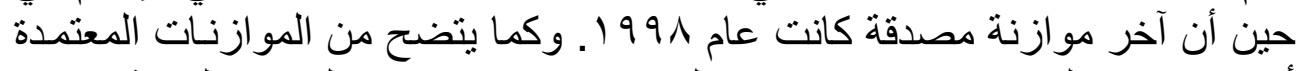

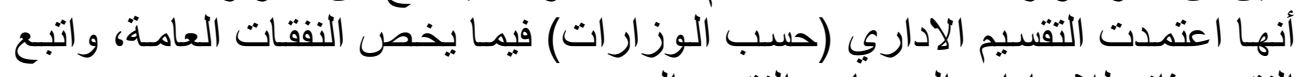

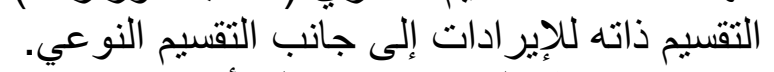

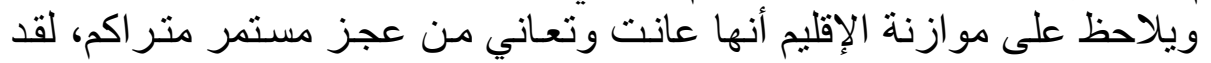

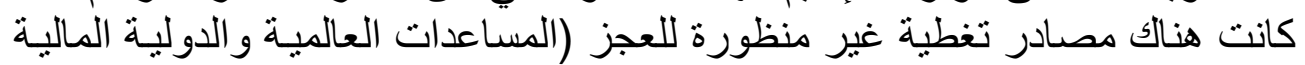

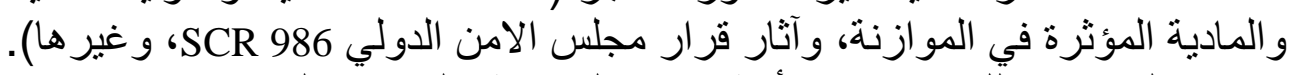

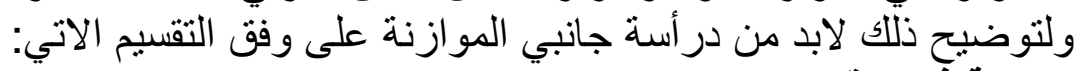

Public Expenditures النفقات العامة في الإقليم لتوني

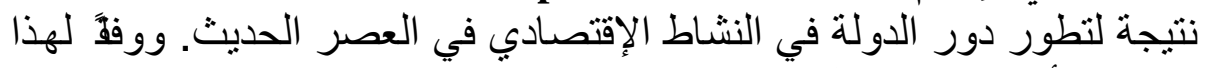

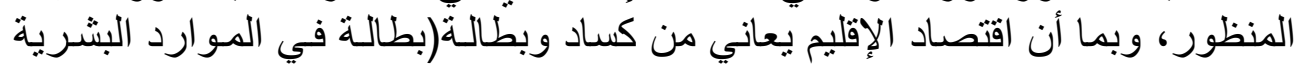




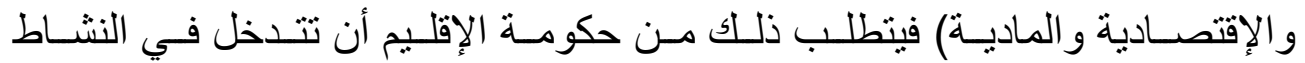

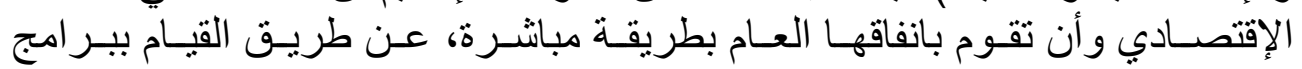

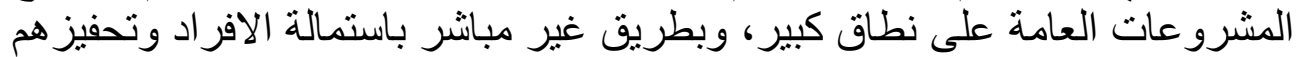

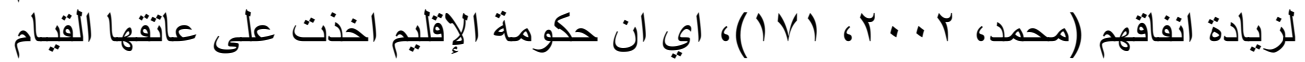

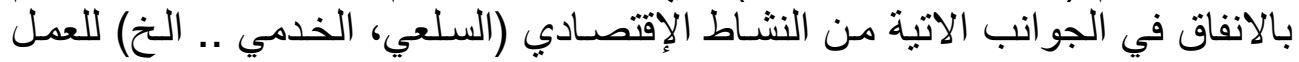

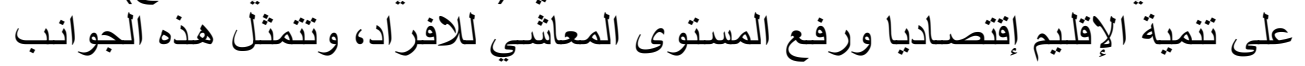

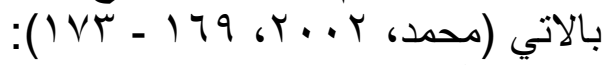
ا ـ تشكيل الحكومة بوز ار اتها المختلفة وتشكيل المؤسسات و والوحدات الاداريـة للقيام

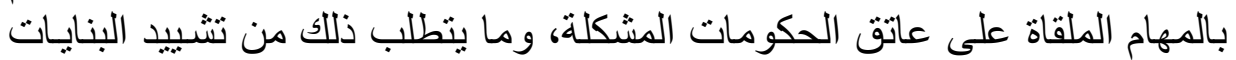

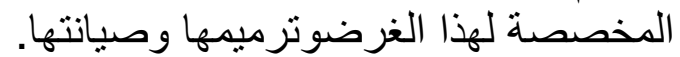

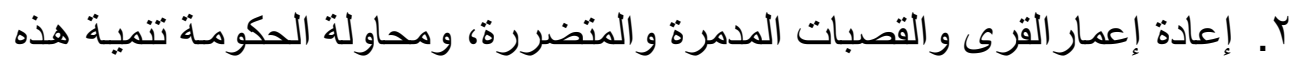

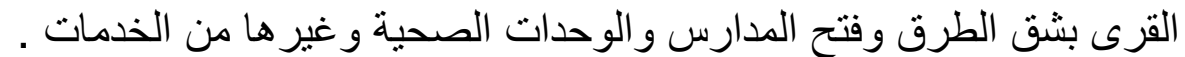

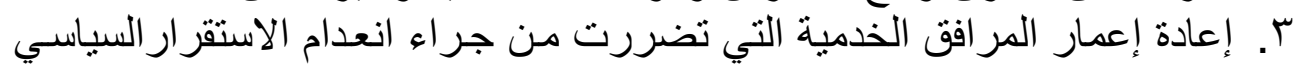

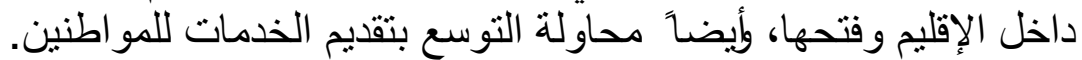

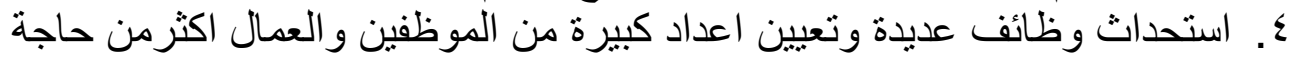

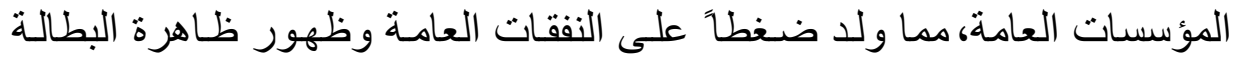
المقنعة. ه. قيام الحكومة بصرف مبالغ للمصارف عن حسابات وودائع المو اطنين التي كانت

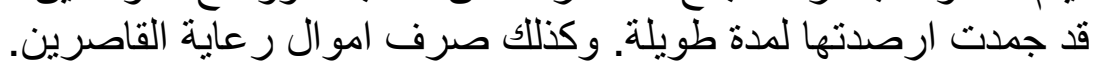

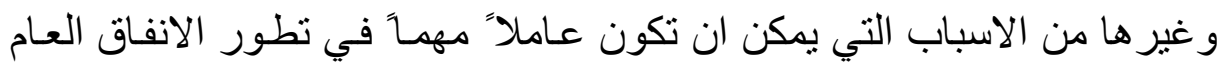

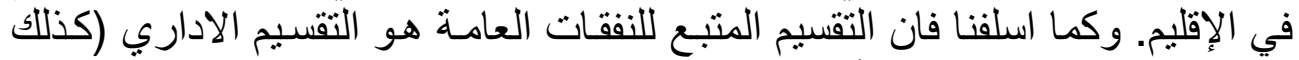

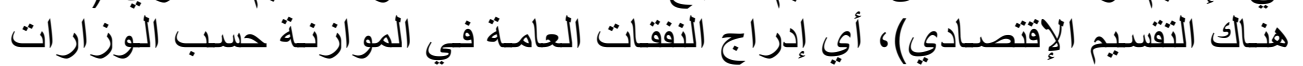

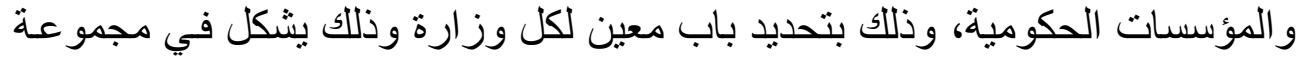

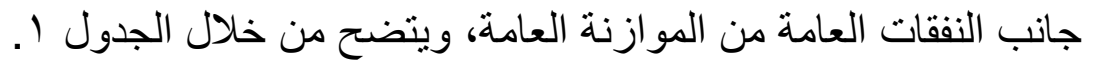

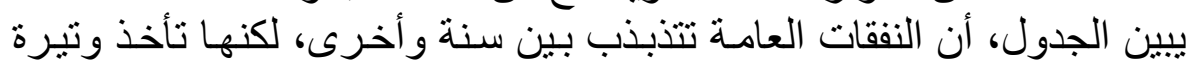

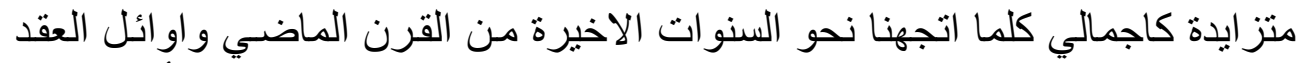

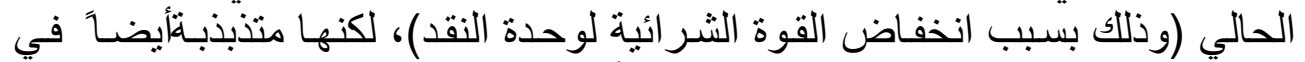

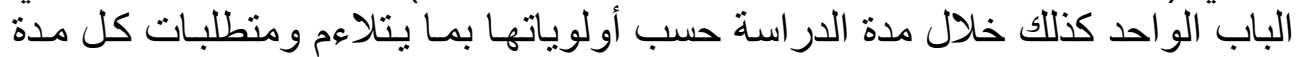

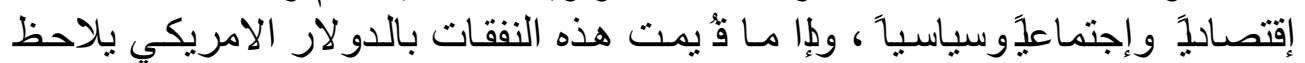
انها تضاعفت كثير ا في الفترة المذكورة وذلك لتحسن سعر صرف التف الدينار.

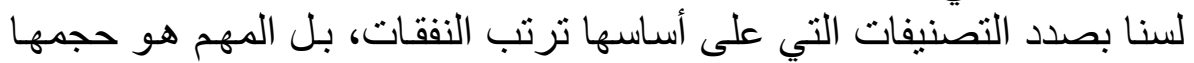
وكونها جانبً مهذً من الموازنة العامة للإقليم. ومن الجدير بالذكر ان النفقات العامـة التهات

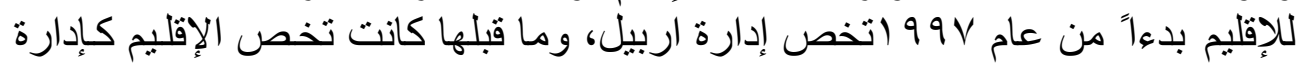


بما أن الحكومة تقوم بالانفاق نتيجة لتطور دور الدولة في الاصعدة كافة، كان

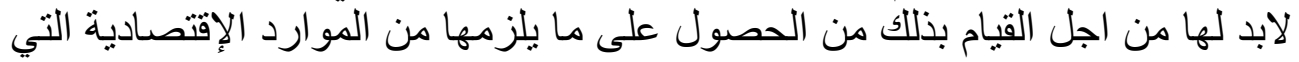

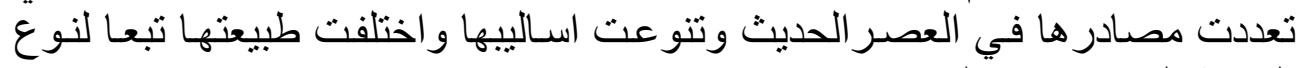
الخدمة التي تقدمها و الهدف منده العها. وقد صنفت إير ادات الإقليموفقاً للنوع (الفصـول) وكذللكووفاً للتقسيم الاداري

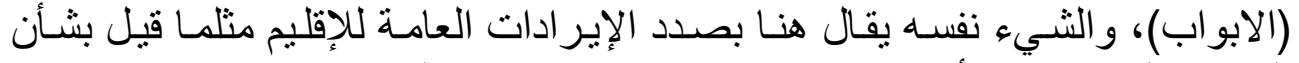

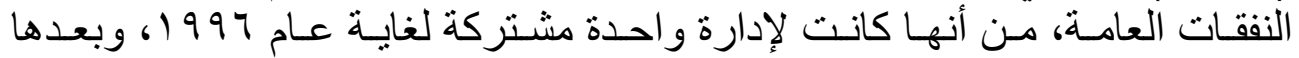

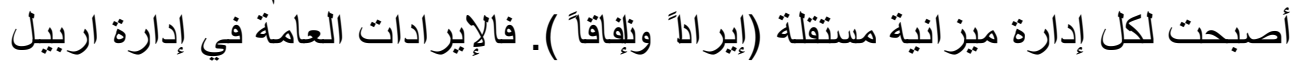

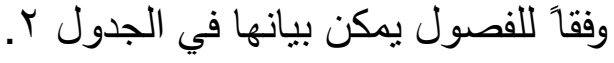

\begin{tabular}{|c|c|c|c|c|c|c|c|}
\hline \multicolumn{8}{|c|}{ 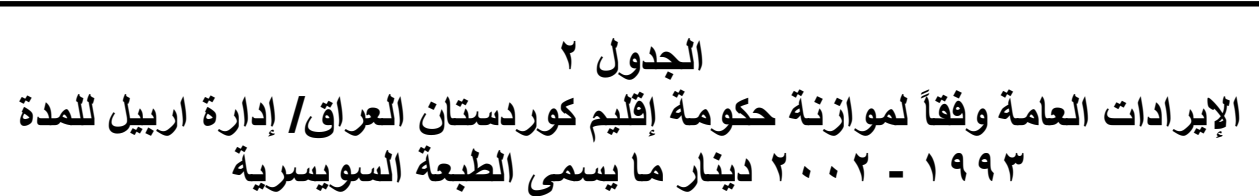 } \\
\hline \multirow{2}{*}{ إلإقاداتي } & \multirow{2}{*}{ غير الضرير الضيبية } & \multirow{2}{*}{ الإيرادات من الضب } & \multicolumn{4}{|c|}{ الضر ائب المباشرة } & \multirow[b]{2}{*}{ السنة } \\
\hline & & & المباشرلي & رأس & الاخل & العقار & \\
\hline 1.1 & TV. & 971 & ror & $T r$ & $r \cdot \Lambda$ & 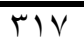 & 1994 \\
\hline 1YO & rqY & 110 & $r \cdot v$ & rYA & rrᄉ & $\{7 \mid$ & 1998 \\
\hline 780 & 790 & $7 \ldots$ & 07. & $\overline{Y Y I}$ & $r \wedge \wedge$ & $r \leqslant q$ & 1997 \\
\hline 174 & 119 & $1 \leqslant 9$ & $r \leqslant 7$ & 111 & $1 \leqslant 9$ & Vqr & 1998 \\
\hline TYE & $r \cdot r$ & 19. & $r v$. & 417 & $r \wedge q$ & 7.1 & 1991 \\
\hline YYO & $r \cdot r$ & $r \cdot 1$ & rVA & $10 Y$ & rr. & Tr & 1999 \\
\hline 107 & $r / r$ & $T r$ & $\Gamma \wedge$. & 150 & $r 10$ & $10 Y$ & $r \ldots$ \\
\hline $1 \leqslant 9$ & YOS & $T r$ & $\varepsilon r \wedge$ & roo & YYO & $I V V$ & $r \ldots$ \\
\hline$\overline{1 \wedge r}$ & $\varepsilon .9$ & $11 \%$ & $\overline{T A Y}$ & $9 \vee$. & OrA & $1 \pi \xi$ & $r \ldots r$ \\
\hline
\end{tabular}

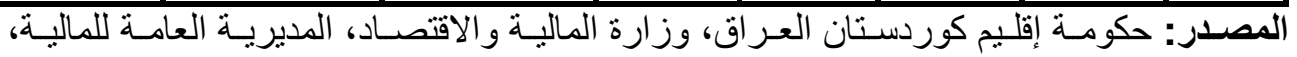

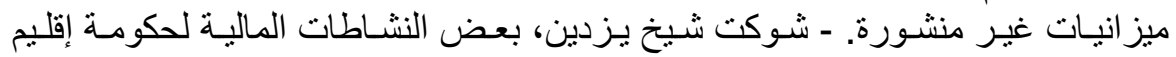

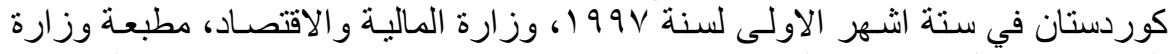

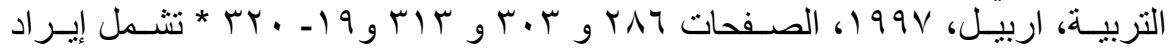

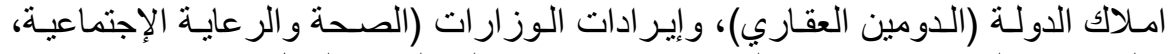

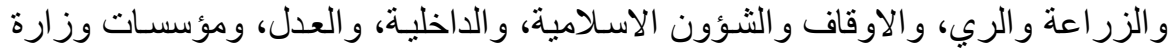

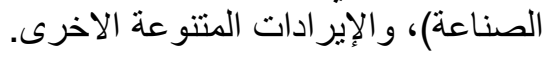

مـن الجدول ب يتبـين أن الإيـرادات على انو اعهـا ضـريبية كانـت ام غيرهـا،

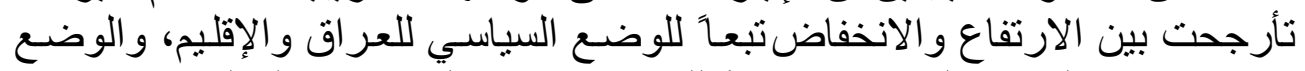

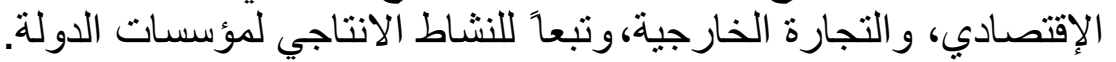

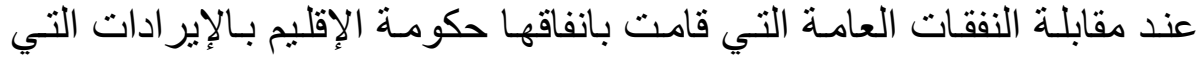

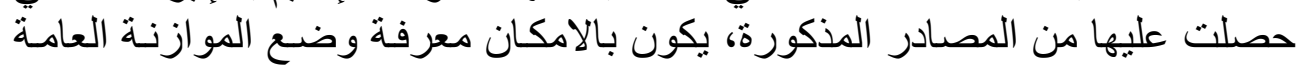




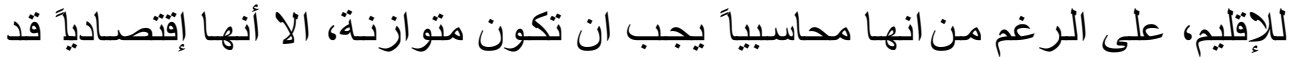

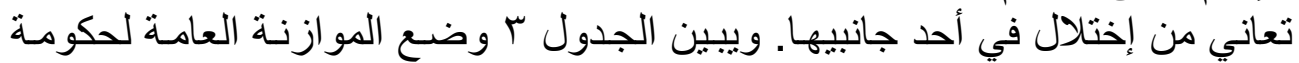
الإقليم.

\section{الجدول r}

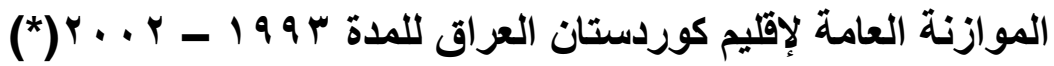
الف دينار سويسري

\begin{tabular}{|c|c|c|c|c|c|c|}
\hline العجز المتراكم & 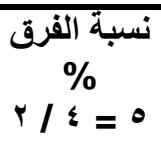 & الفرق بينهما & $\begin{array}{c}1 / r=r \\
\%\end{array}$ & الإيراداث & النققات & السنة \\
\hline YI. & $r$. & YI. - & $\overline{N Y}$ & 1.1 & ITY & 1994 \\
\hline $7 Y 0$ & Tr & $\varepsilon) \leqslant-$ & vo & 1ro & 177 & 1998 \\
\hline r97 & $\sum \lambda$ & rrq & 190 & $7 \vee 0$ & $r \leqslant 0$ & 1997 \\
\hline $91 \varepsilon$ & rv & $711-$ & $V Y$ & 174 & rYo & 1998 \\
\hline $1 V \varepsilon$ & T4 & AYV - & $V T$ & TYE & $r \cdot v$ & 1991 \\
\hline$r \varepsilon \varepsilon$ & $r$. & $7919-$ & $V 7$ & TrO & 190 & 1999 \\
\hline 5.79 & $\varepsilon$. & TYA - & $\overline{v 1}$ & 107 & 119 & $r \ldots$ \\
\hline rᄉ. & $\varepsilon 9$ & VTu - & $7 V$ & $1 \leqslant 9$ & TYM & $r \ldots 1$ \\
\hline sor & rq & VYV - & V) & 111 & roo & $r \ldots r$ \\
\hline
\end{tabular}

المصدر : اعد الجدول بالاعتماد على الجدولين ا و و ب النسب من احتساب الباحثين.

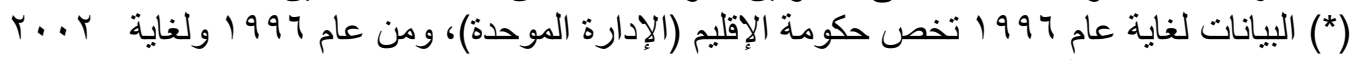

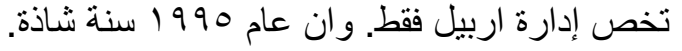

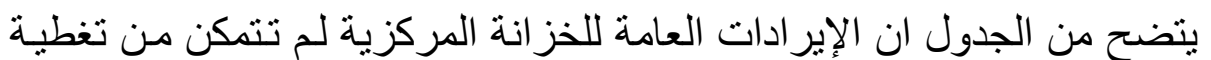

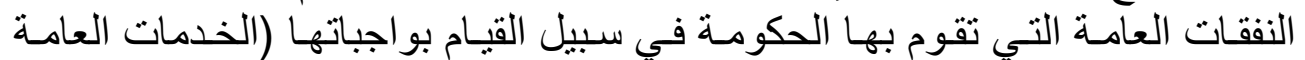

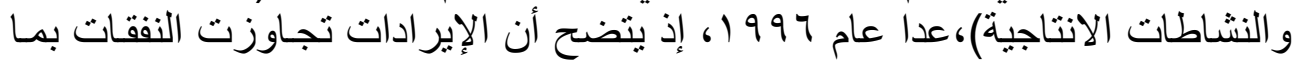

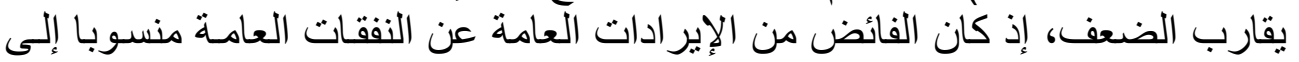

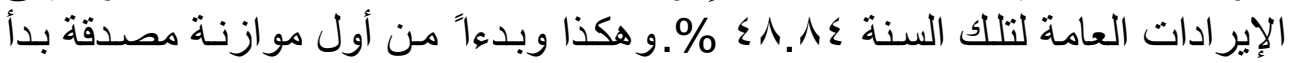

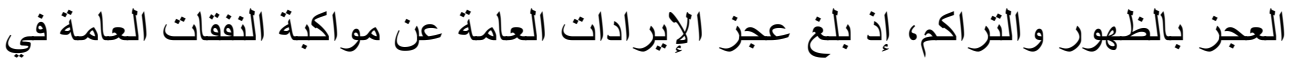

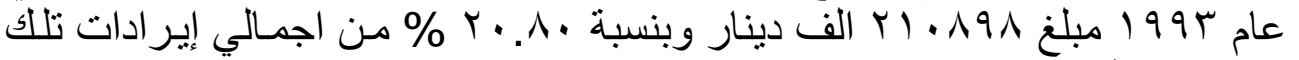

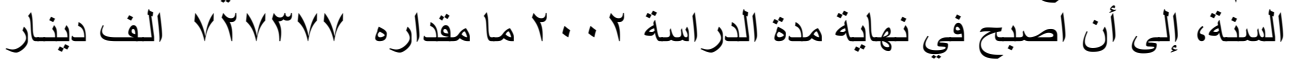

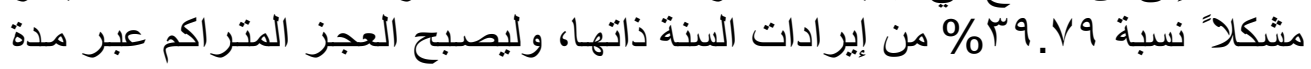

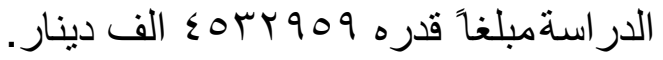

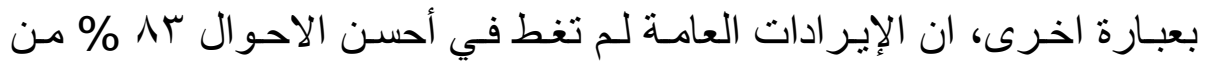

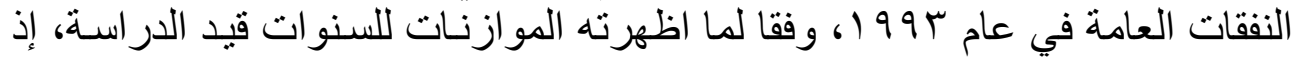

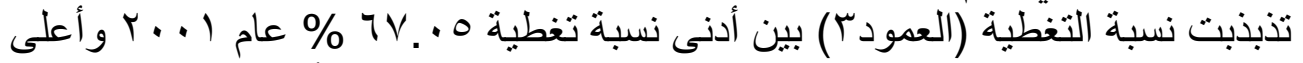

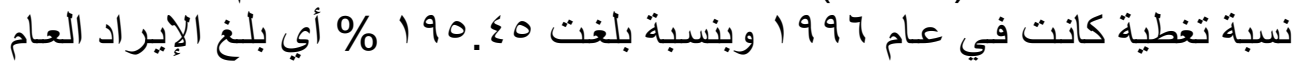
فيها ما يقارب ضعفي النفقات العامة. 


\section{الإيرادات المتحققة من ضريبة العقار}

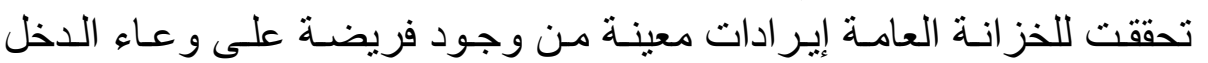

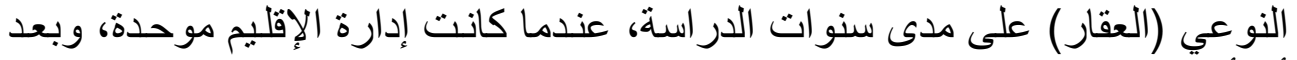

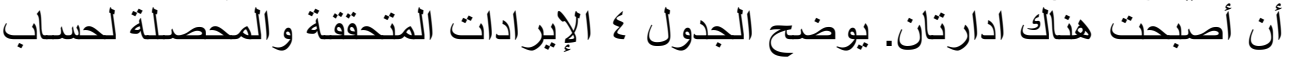

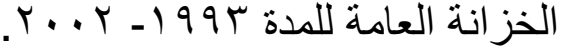

\begin{tabular}{|c|c|c|c|c|c|}
\hline دقينار سويسرى & ت المكونة & 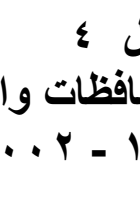 & للار حدة حسب & ضر & \\
\hline \multirow{2}{*}{ إيراد الضالضريبة } & \multirow{2}{*}{ السليمانية } & \multicolumn{3}{|c|}{ إدارة اربيل } & \multirow[t]{2}{*}{ السنة } \\
\hline & & المجموع & دهوك & اربيل & \\
\hline rIV & $19 \varepsilon$ & ITr & -------- & ITr & 1994 \\
\hline$\sum 71$ & $r \cdot r$ & 101 & -------- & 101 & $199 \varepsilon$ \\
\hline ६१V & $r \leqslant \Lambda$ & $r \leqslant 9$ & |------- & $r \leqslant q$ & 1997 \\
\hline $1 \% 0$ & $\varepsilon 7 \varepsilon$ & Vqr & TrE & 579 & $199 V$ \\
\hline ITY & TYT & 7.1 & 1.7 & $\leqslant 90$ & 1991 \\
\hline$r \mu q$ & 1.0 & ITr & $7 \leqslant \Lambda$ & $7 \wedge V$ & 1999 \\
\hline$\overline{T V V}$ & $1 \% 0$ & 104 & $v \varepsilon r$ & VAr & $r \ldots$ \\
\hline roo & $1 V V$ & IVV & $\lambda \varepsilon$. & 947 & $r \ldots l$ \\
\hline$r \cdot r$ & $17 V$ & $1 \Gamma \varepsilon$ & ro & 1.9 & $\overline{r \ldots r}$ \\
\hline
\end{tabular}

المصدر: وزارة المالية و الاقتصاد، مديرية ضريبة عقار اربيل، بيانات غير منشورة.

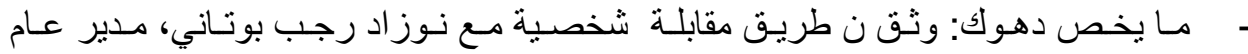

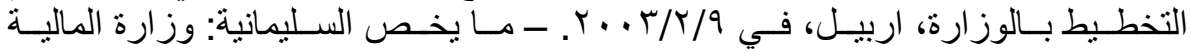
و الاقتصاد، المديرية العامة للضر ائب، السليمانية، بيانات غير منشورة .

من متابعة الجدول ع يتبين ان ضريية العقار بالأسعار الجارية في الإقليم

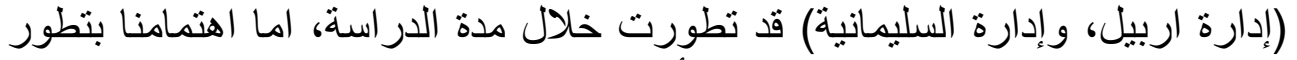

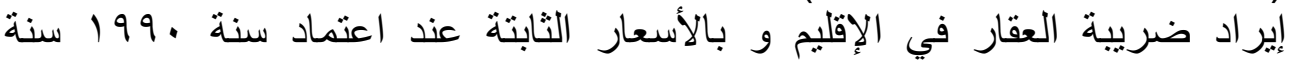

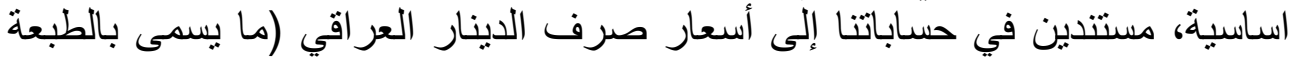

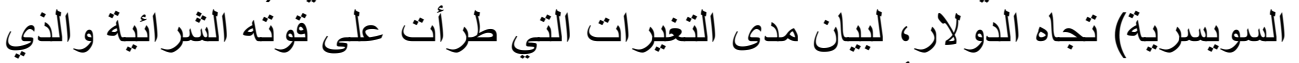

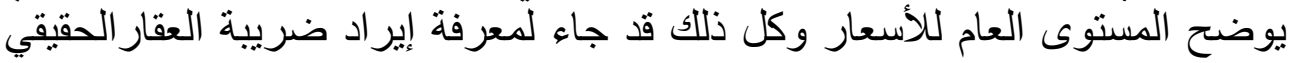

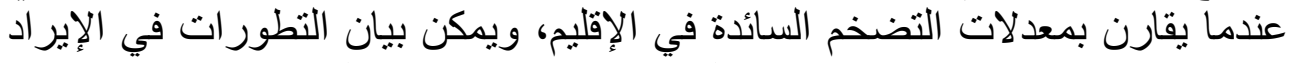

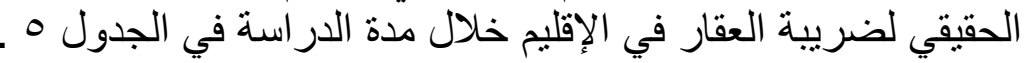

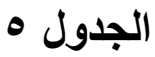

حصيلة إيراد ضريبة العقارفي الإقليم بالأسعار الثابتة 


\begin{tabular}{|c|c|c|c|c|c|c|c|c|}
\hline \multicolumn{3}{|c|}{ إيراد ضريبة العقار/إدارةالسليمانية } & \multicolumn{3}{|c|}{ إيراد ضريبة العقار/إدارة اربيل } & \multirow{2}{*}{ رقمّ قياس } & \multirow{2}{*}{ سبر صرف الدينار } & \multirow[t]{2}{*}{ السنة } \\
\hline نسبة النمو & أسعار ثُابتة & أسعار جارية & نسبة النمو & أسعار ثنابتة & أسعار جارية & & & \\
\hline-- & $r .0 . r \varepsilon$ & $19 \leqslant r .79$ & ---- & $1940 \leqslant 7$ & IYTYANT & $7 \pi v$ & $r q . . v v$ & 1994 \\
\hline$v_{.} .$. & หภrรт9 & $r . r+q 11$ & หr१ะ- & $1 \leq 910 r$ & $101990 \mathrm{~V}$ & 1.77 & $70 . Y \Lambda$. & $199 \leqslant$ \\
\hline$\{9.91$ & $\leqslant$ YOY $\leqslant 9$ & TEAVOOV & $1 \leq . .10$ & roN191 & $r \leqslant 91 r 79$ & $v \cdot \Lambda$ & हr. ז. & 1990 \\
\hline$\varepsilon \varepsilon . \varepsilon T$ & $71 \varepsilon$ & $\leqslant 7 \leqslant$ & $v . V \varepsilon$ & 710 & VqT & $\varepsilon .0$ & T乏.VAY & 1997 \\
\hline AV.YT & 110 & $7 Y 7$ & TIV.Pr & 190 & 7.1 & $\varepsilon \cdot v$ & $r \varepsilon .9 \varepsilon \cdot$ & $199 \mathrm{~V}$ \\
\hline$\leqslant 0.9 V$ & $17 V$ & 1.0 & IV.Yq- & 171 & Tr & $\overline{r V T}$ & TY.A乏. & 1991 \\
\hline $1 \cdot . \varepsilon$ & rro & Tro & $17 r . \wedge 1$ & $\varepsilon r \xi$ & 104 & $r 10$ & $19 . r$. & 1999 \\
\hline ro.r. & $\varepsilon r$. & IVV & $Y \cdot . V T$ & 011 & IVV & $r 91$ & IN.TV. & $r \ldots$ \\
\hline$\sum r .01$ & 099 & $17 \mathrm{~V}$ & IV.Y9 & $7 \ldots$ & $1 \pi \varepsilon$ & r97 & $11.1 \leqslant r$ & $r \ldots l$ \\
\hline $9 . \cdot \varepsilon-$ & $0 \leqslant 0$ & $19 \varepsilon$ & $r V . r \leq-$ & 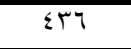 & Trr & $r \cdot \Lambda$ & $1 \wedge . \wedge \wedge$. & $r \cdots r$ \\
\hline
\end{tabular}

المصدر: أسعار الصرف: محمد سلمان محمد، أسباب تذبذب قاب قيمة الدينار العراقي بالإقليم، مجلة

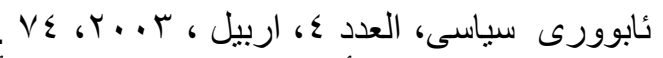

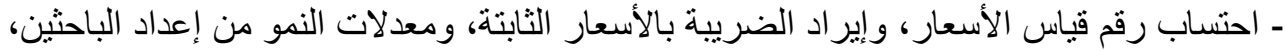

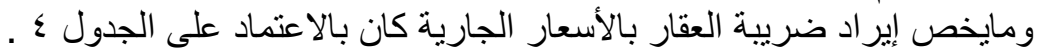

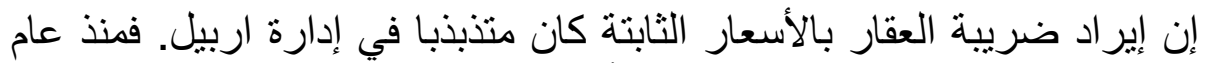

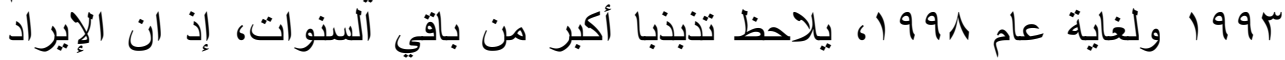

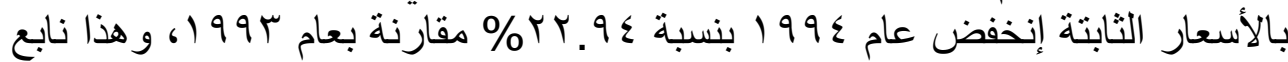

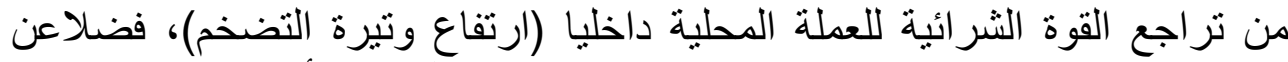

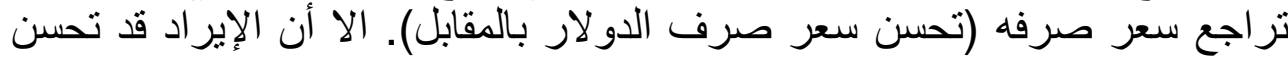

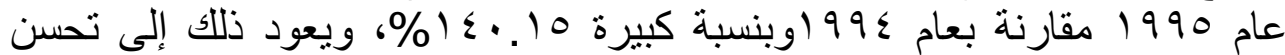

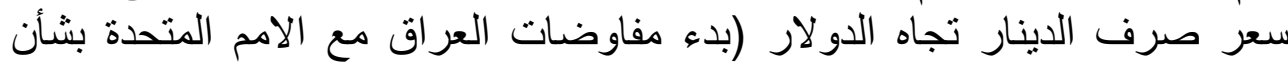
برنامج النفط مقابل الغذاء و الدواء)، فضلاعن تحسن نسبي في قوته الثرائية دائه داخليا

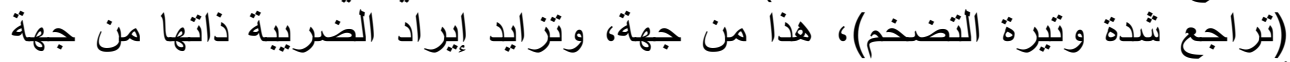
أخرى. و هكذا الحال بين نمو ايجابي ونموسلبي، وبوتيرة غير متجانسة خلال مدة

و الثيء نفسه يقال بخصوص إير اد ضريبة العقار بالأسعار الثابتة في إدارة

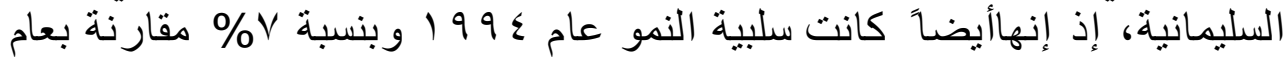

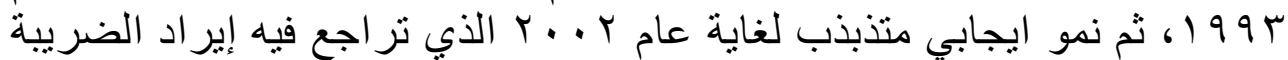

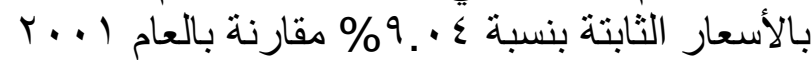

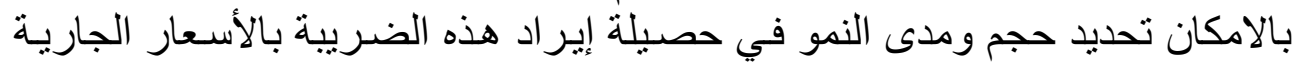
في الإقليم، وكذلك تحديد إتجاه نموها خلال تلك المدة بالجدولين 0 و 7.

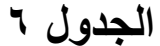

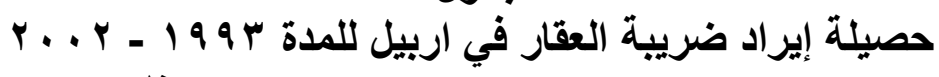
دينار سويسري 


\begin{tabular}{|c|c|c|c|c|c|}
\hline الزمن t & الزمن t & نسبة النمو \% & مقدار النمو & إيراد الضريية & السنة \\
\hline 1 & 1 & --- & ------ & Tr & 1994 \\
\hline$\varepsilon$ & $r$ & rA.9 & rov & 101 & 1998 \\
\hline 9 & $r$ & 09.0 & $9 \leqslant 7$ & Tor & 1990 \\
\hline 17 & $\bar{\varepsilon}$ & $1 . V-$ & $\varepsilon \leqslant 7-$ & $r \leqslant q$ & 1997 \\
\hline TO & $\overline{0}$ & $\overline{\Lambda \Lambda . r}$ & 199 & $\sum 79$ & $199 V$ \\
\hline ru & 7 & 0.0 & rT. & $\leqslant 90$ & 1991 \\
\hline$\varepsilon 9$ & V & rᄉ. 9 & 194 & TAV & 1999 \\
\hline $7 \varepsilon$ & $\Lambda$ & $1 T . \Lambda$ & 90. & VAY & $r \ldots$ \\
\hline (1) & 9 & 19.8 & 105 & 947 & $r \ldots l$ \\
\hline $1 \ldots$ & 1 . & 17.8 & $10 V$ & 1.9 & $r \ldots r$ \\
\hline
\end{tabular}

المصدر: اعد الجدول من قبل الباحثين بالاعتماد على الجدول ؛. ـ احتسب مقدار النمو و النسب من قبل الباحثين .

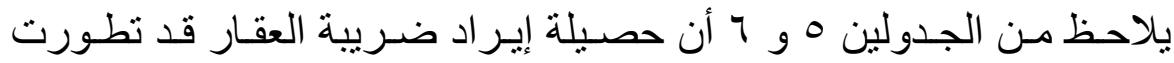

بصورة مستمرة في الإقليم خلال مدة الدر اسة ، وقد يعود ذللك إلى العو امل الاتية :

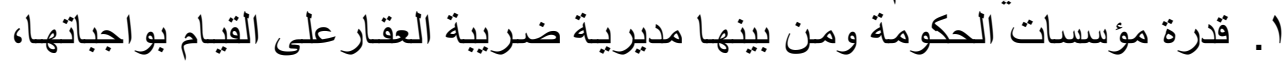

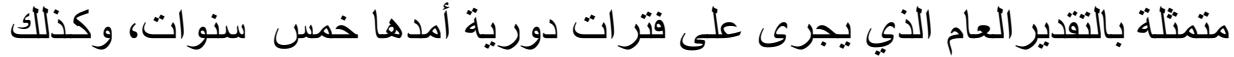

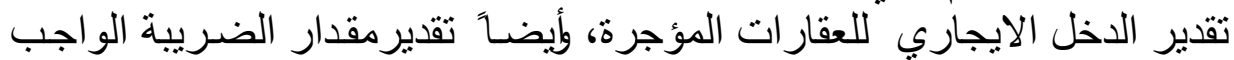

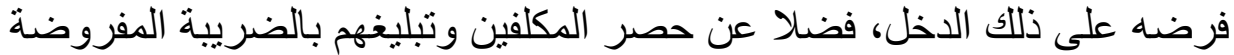
r. توسع في حجم العقار ات المؤجرة (وعاء الضريبة) لمختلف الاغر اض (السكنى الاضى

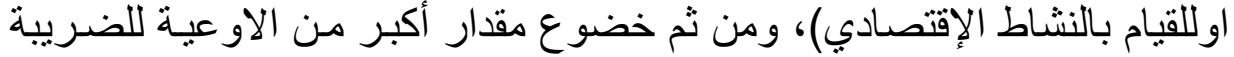

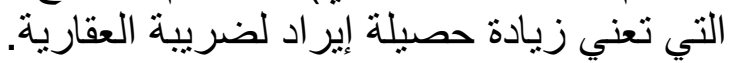
r. . استخدام الإدارة الضريبية وسـائل مختلفة لتحصيل الضـريبة (العقاريـة و غيرهـا

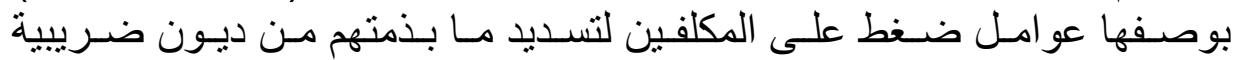
لتساعدهم في الحصول على الخدمة او المنفعة التي تقدمها مؤسسات الحكومة لفئ.

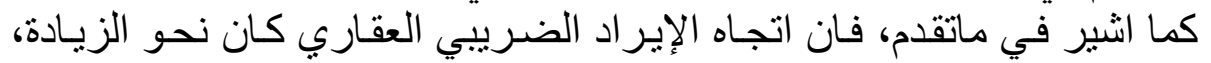

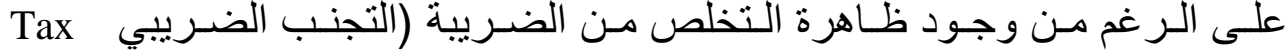
Avoidance

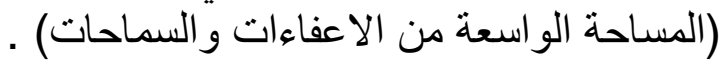

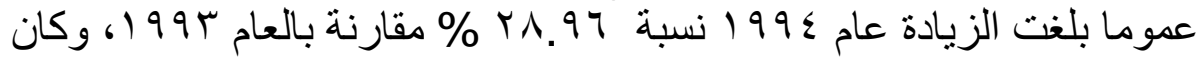

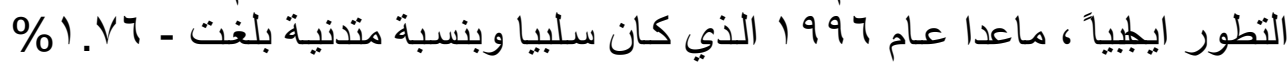

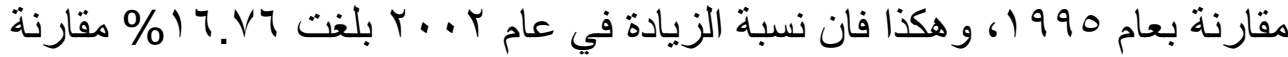

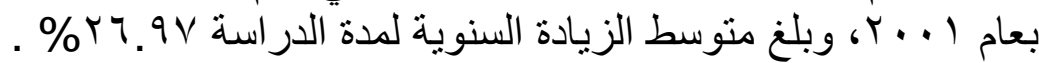

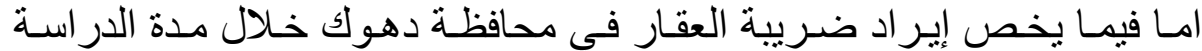

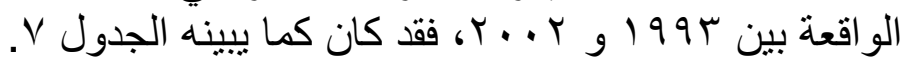




\begin{tabular}{|c|c|c|c|c|c|}
\hline سويسري & د. & لمدة ب 9 ج & اللعقار فئي & صيلة إيراد & \\
\hline $\begin{array}{c}\text { الزمن } \\
T^{2}\end{array}$ & $\begin{array}{c}\text { الزمن } \\
\text { T }\end{array}$ & نسبة النمو \% & مقدار النمو & إيراد الضريبة & السنة \\
\hline 1 & 1 & --- & ------- & ------- & 1994 \\
\hline$\varepsilon$ & r & ---- & ------- & ------- & $199 \leq$ \\
\hline 9 & $r$ & --- & ------- & ------- & 1990 \\
\hline 17 & $\varepsilon$ & $\overline{----}$ & ------- & $\begin{array}{l}------ \\
\end{array}$ & 1997 \\
\hline ro & 0 & ---- & ------- & rrs & $199 V$ \\
\hline ד & 7 & $7 V .1-$ & Y\人 - & 1.7 & 1991 \\
\hline$\leqslant 9$ & V & $0.1 . r$ & $0 \leqslant 1$ & $7 \leq \Lambda$ & 1999 \\
\hline $7 \varepsilon$ & $\Lambda$ & $1 \leqslant .7$ & 901 & $V \leqslant T$ & $r \ldots$ \\
\hline 11 & 9 & 11.1 & $9 \vee 7$ & $\Lambda \varepsilon$. & $r \ldots 1$ \\
\hline $1 \ldots$ & $1 \cdot$ & $v \cdot . \cdot$ & $O \wedge \Lambda-$ & rol & $r \ldots r$ \\
\hline
\end{tabular}

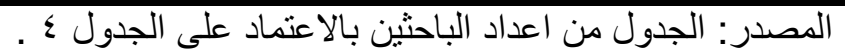

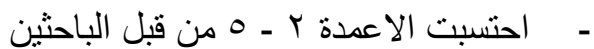

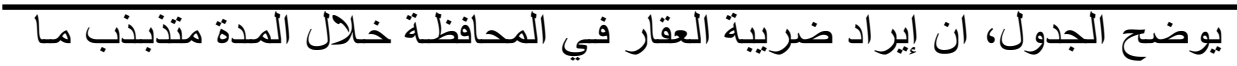

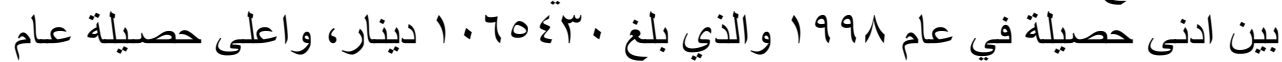

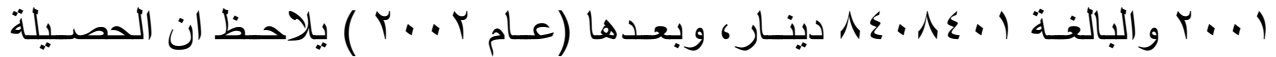

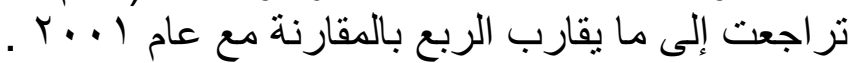

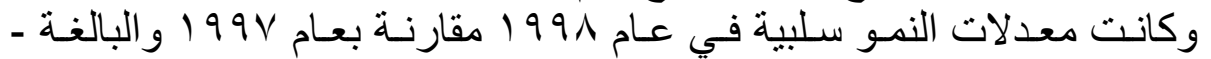

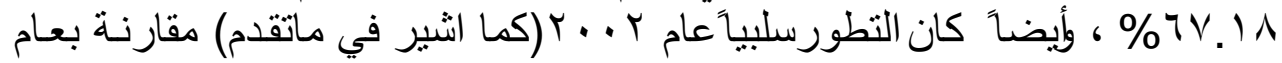

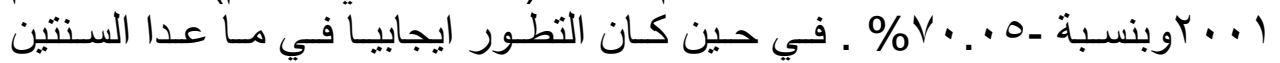

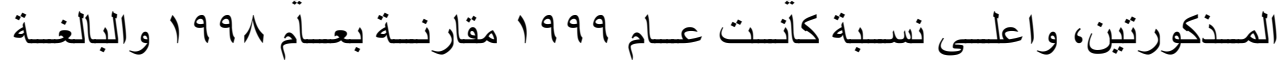

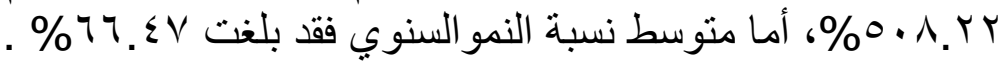

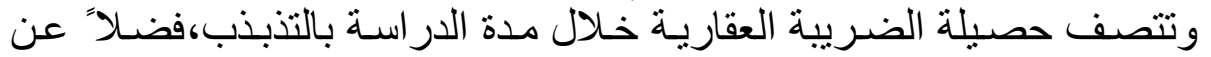

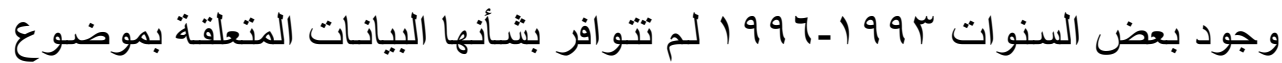
الدر اسة. وقد يعود سبب التذبذب إلى جملة عو امل منها إيجابي ومنها سلبي على تللك

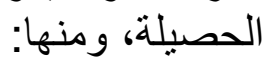

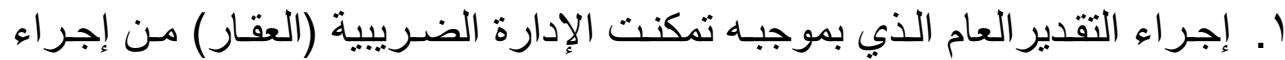

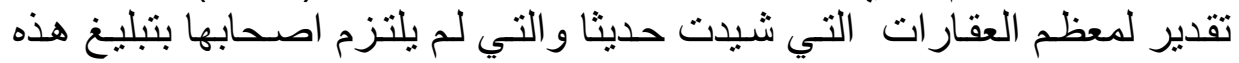

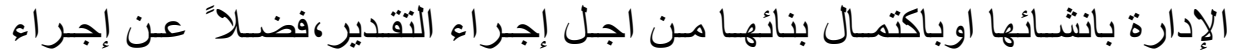

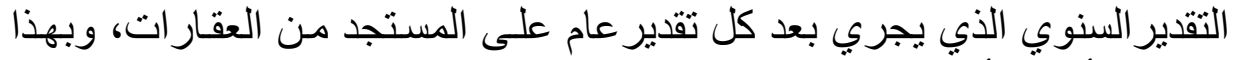
خضعت أوعية أوسع للضريبة الضية. 


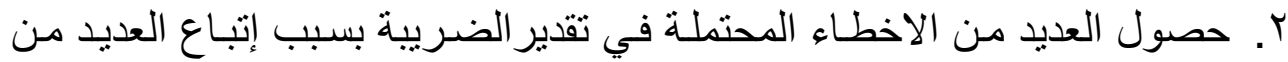

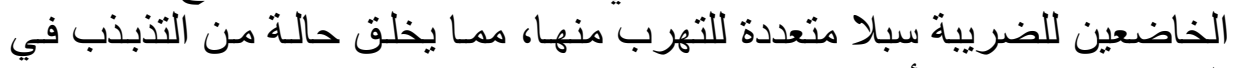
التقدير ات بين سنة و أخرى.

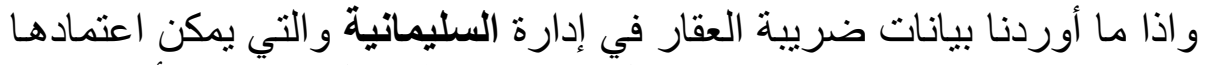

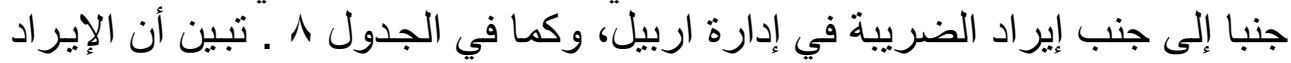

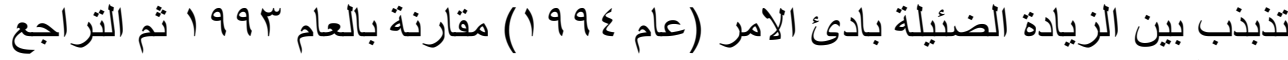

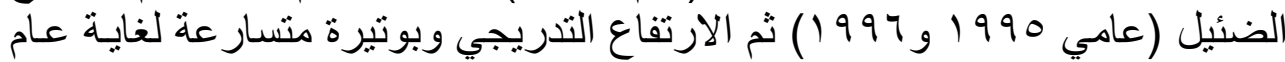

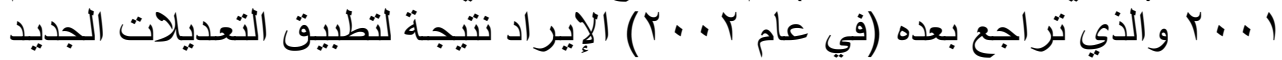
على قانون ضريبة العقار (اعفاء وسماح وتغيير مقياس الضرئ الضريبة و الثرائح).

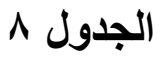

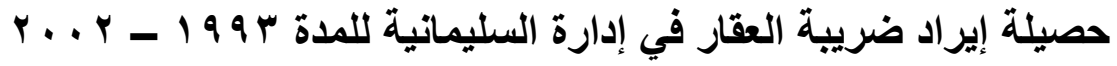

\begin{tabular}{|c|c|c|c|}
\hline نسبة النمو \% & مقدار النمو & إيراد الضريبة & السنة \\
\hline---- & ------- & 195 & 1994 \\
\hline 00.74 & $1 \cdot 1$ & $r \cdot r$ & $199 \varepsilon$ \\
\hline$\cdot \varepsilon \Gamma-$ & - & $r \cdot 1$ & 1990 \\
\hline IV.r - & OYT - & $r \leqslant \Lambda$ & 1997 \\
\hline 17.0 & Y10 & $\leqslant 7 \leqslant$ & $199 V$ \\
\hline$r \varepsilon .9$ & 174 & TY7 & 1991 \\
\hline 71.9 & $\sum \pi$ & 1.0 & 1999 \\
\hline $11 . \varepsilon$ & 190 & Tro & $r \ldots$ \\
\hline$\leqslant 1.7$ & orl & IVV & $r \ldots r$ \\
\hline $0.10-$ & $9 \leq 9-$ & $17 V$ & $r \ldots r$ \\
\hline
\end{tabular}

المصدر: الجدول من اعداد الباحثين بالاعتماد على الجدول رقم ؟ .- احتسبت الاعمدة ؟ - 0 من قبل الباحث. لون.

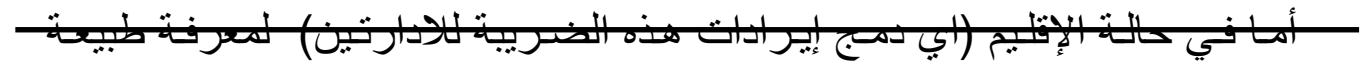
العلاقة بين إير اد ضـريبة العقار و الزمن ومسـار وطبيعـة النمـو في هذا الإير اد مـع

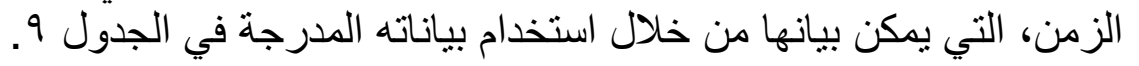

\begin{tabular}{|c|c|c|c|c|c|}
\hline $\begin{array}{r}r . . r \\
\\
\end{array}$ & 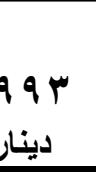 & ونتان العراق للا & في إقليم كر & و الجدول 9 & حصب \\
\hline الزمن & الزمن & نسبة النمو \% & مقدار النمو & إيراد الضريبة & السنة \\
\hline$T$ & $\overline{1}$ & $\begin{array}{l}--- \\
\end{array}$ & $\begin{array}{l}------ \\
\end{array}$ & TIV & 1994 \\
\hline$\varepsilon$ & $r$ & $\varepsilon 0 . Y$ & $1 \leqslant r$ & $\sum 71$ & 1998 \\
\hline 9 & $r$ & $r \cdot . r$ & $9 \pi r$ & $00 \leqslant$ & 1990 \\
\hline 17 & $\varepsilon$ & $1 \cdot . Y-$ & $07 V-$ & $\varepsilon 9 V$ & 1997 \\
\hline
\end{tabular}




\begin{tabular}{|c|c|c|c|c|c|}
\hline ro & 0 & 104.7 & 1809 & $1 \% 0$ & $199 \mathrm{~V}$ \\
\hline$r$ & 7 & r.r人 - & rq9- & ITK & 1991 \\
\hline ₹9 & V & $9 \leqslant .9$ & 117 & rrq & 1999 \\
\hline$T \varepsilon$ & $\Lambda$ & 17.1 & rıo & $T V V$ & $r \ldots$ \\
\hline 11 & 9 & $r V . \wedge$ & $V V T$ & roo & $r \ldots l$ \\
\hline $1 \ldots$ & 1. & $1 \leqslant . \wedge-$ & OYY - & $r \cdot r$ & $r \ldots r$ \\
\hline
\end{tabular}

المصدر : الجدول من اعداد الباحثين بالاعتماد على الجدول ع.

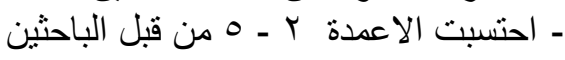

\section{موقع إيرادات ضريبة العقار بين مصادر تمويل الموازنة العامة بالإقليم}

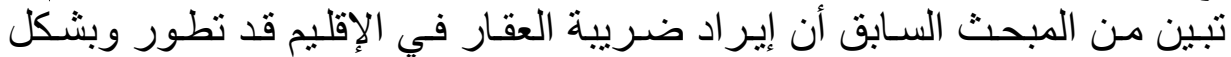

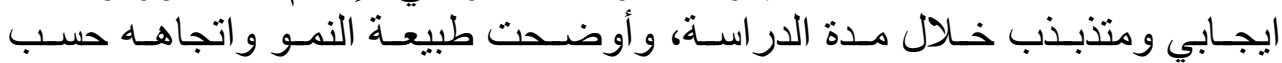

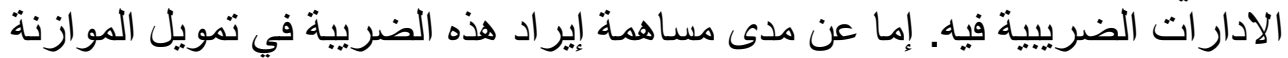

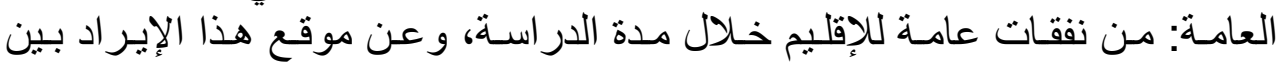

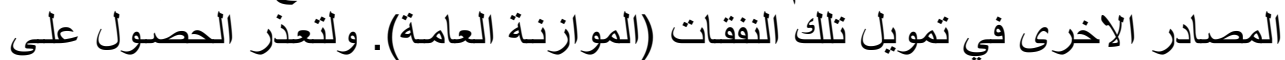

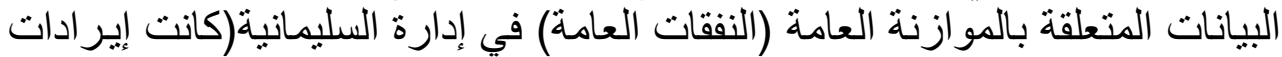

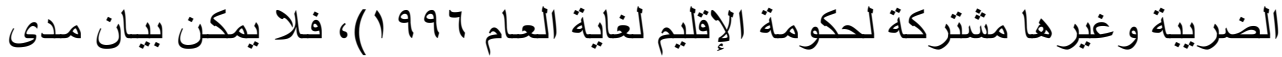

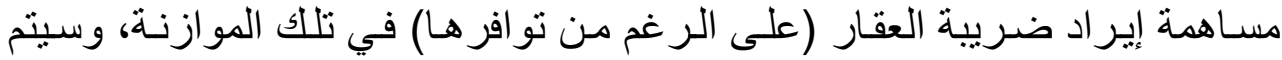

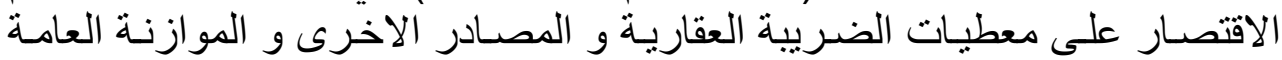

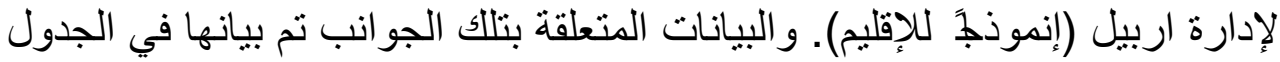

الذي يبين مصادر إير ادات الحكومة (مصادر تمويل الموازنـة او النفقات العامـة)

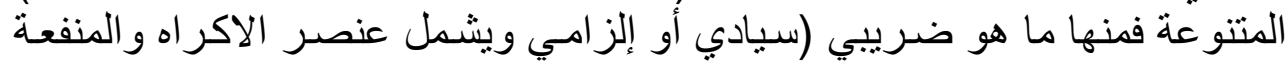

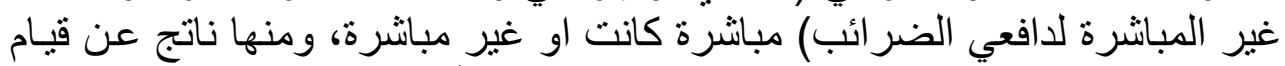

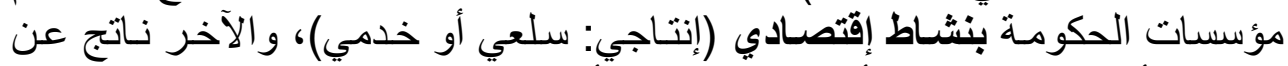

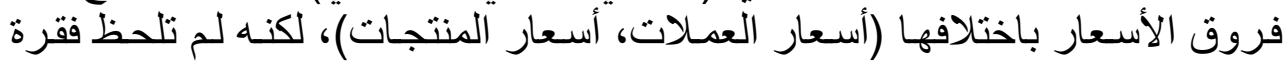

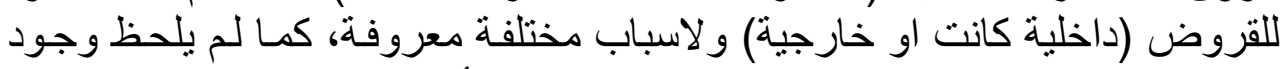

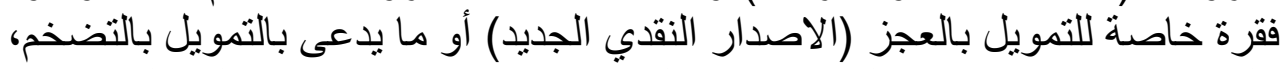

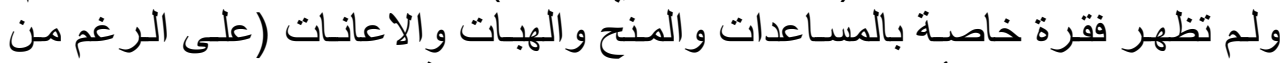

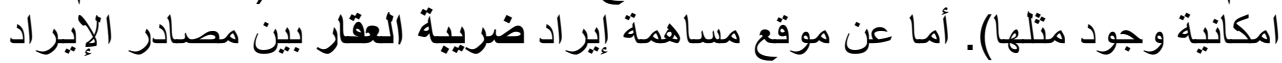

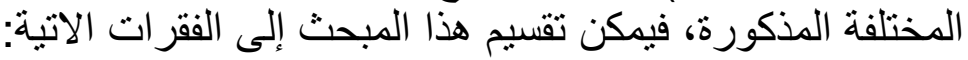

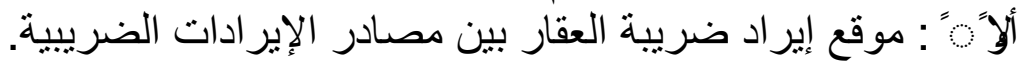

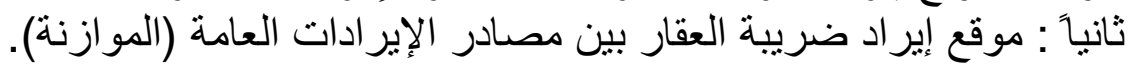

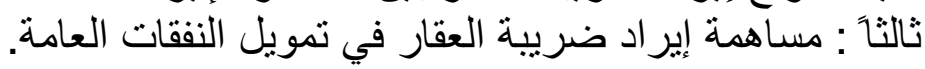

\section{أولاً - موقع إيراد ضريبة العقار بين مصادر الإيرادات الضريبية}




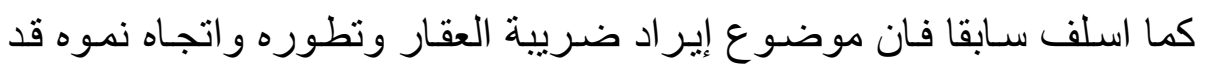

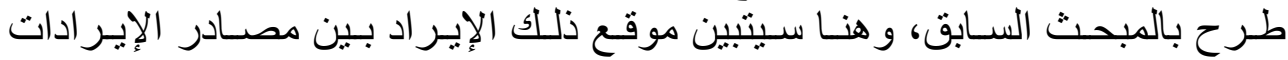

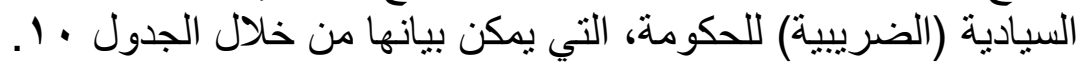

\begin{tabular}{|c|c|c|c|c|c|c|c|c|c|}
\hline \multicolumn{10}{|c|}{ 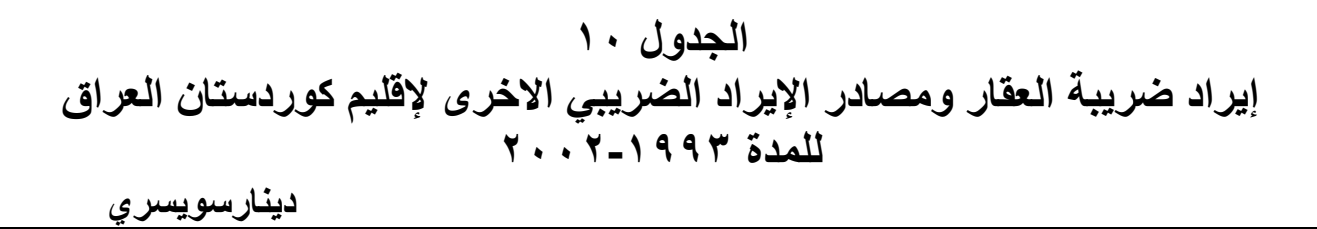 } \\
\hline $\begin{array}{c}0: 1 \\
\%\end{array}$ & الإيرادة & $\begin{array}{l}\varepsilon: 1 \\
\%\end{array}$ & الضريبية & $\begin{array}{c}r: 1 \\
\%\end{array}$ & الضربـائب المب & $\begin{array}{l}r: 1 \\
\%\end{array}$ & ضريبة & ضريبة & السنة \\
\hline$\cdot . r 1$ & 1.1 & $\cdot . r Y$ & 914 & 14.0 & ror & 10.1 & $r \cdot \Lambda$ & TIV & 1994 \\
\hline$\cdot r V$ & Tro &. .49 & 111 & 10. & $r \cdot V$ & 19.4 & $r \mu \wedge$ & $\{7\}$ & $199 \varepsilon$ \\
\hline$\cdot r V$ & TVO & 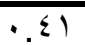 & 7.0 & $\varepsilon \varepsilon . \varepsilon$ & 07. & Nฯ.Y & $r \wedge \Lambda$ & $r \leqslant 9$ & 1997 \\
\hline 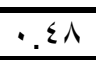 & 174 & $.0 Y$ & 101 & r..1 & $r \leq 7$ & Or.Y & $1 \leq 9$ & V9T & $199 \mathrm{~V}$ \\
\hline$\cdot r V$ & TYE & 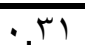 & $19 \varepsilon$ & 17.4 & $r v$. & $r \cdot . \wedge$ & r^q & 7.1 & 1991 \\
\hline .09 & TYO & .70 & $r .0$ & ro.ro & rVA & $01 . . r$ & Tr. & TrT & 1999 \\
\hline$\because 9 V$ & 107 & 1.14 & $1 \pi \varepsilon$ & $\varepsilon \cdot . \cdot V$ & $r \wedge$. & $V \cdot . V \varepsilon$ & 510 & 104 & r... \\
\hline 1.11 & $1 \leq 9$ & $1 . \varepsilon r$ & $1 K \varepsilon$ & $\varepsilon \cdot .0 Y$ & $\sum r \Lambda$ & $\vee \wedge . \wedge \varepsilon$ & KYO & IVV & $r \ldots 1$ \\
\hline$\because V \varepsilon$ & 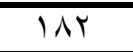 & .90 & $1 \leqslant 1$ & 19.81 & TAY & $r \leqslant .99$ & $0 \mathrm{OH}$ & $1 \pi \varepsilon$ & $r \ldots r$ \\
\hline
\end{tabular}

$$
\text { يتضح من الجدول ما ياتي: }
$$

• • أهمية إيراد ضريبة العقار إلى اجمالي إيراد الضرائب المباشرة

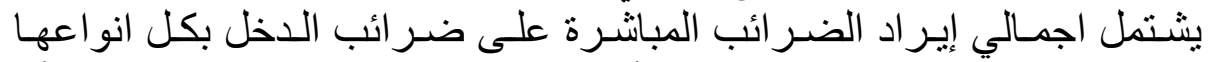

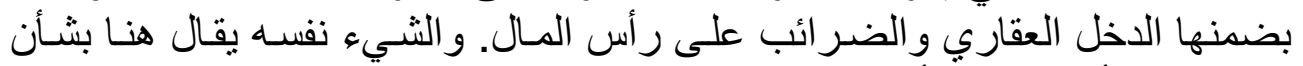

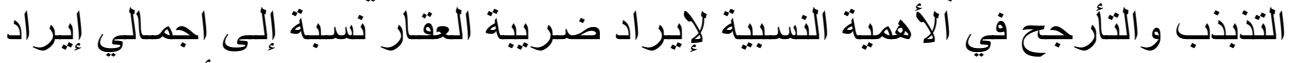

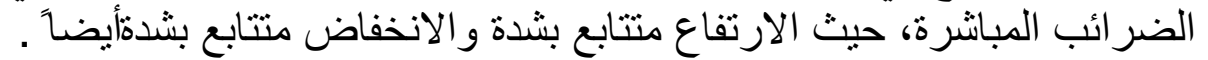

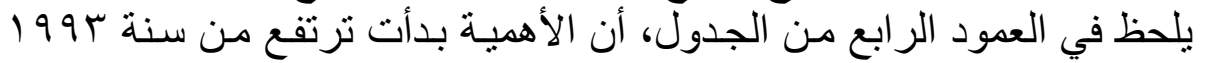

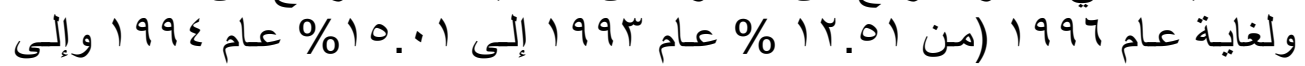

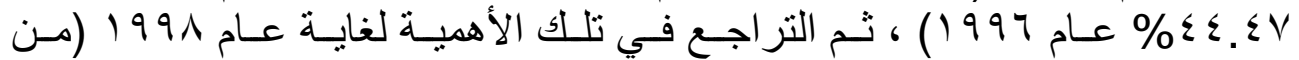

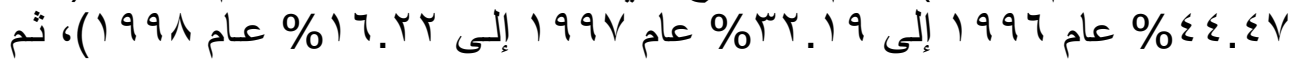

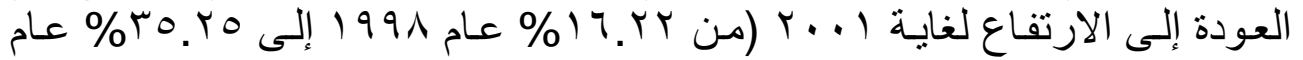

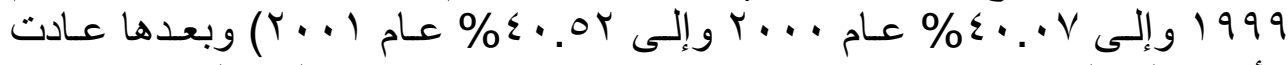

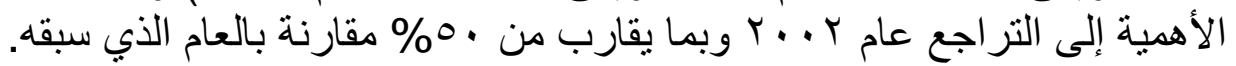




\section{• أهمية إيراد ضريبة العقار إلى اجمالي الإيرادات الضريبية}

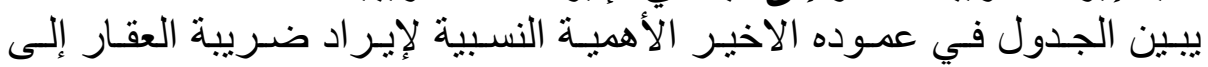

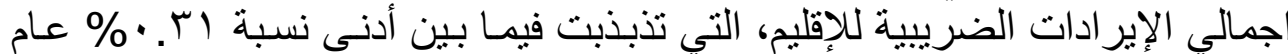

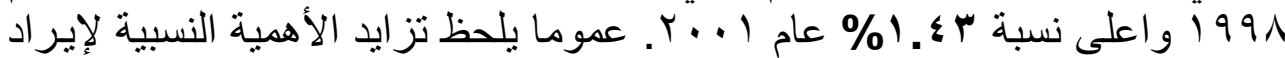

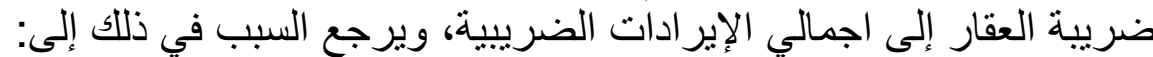

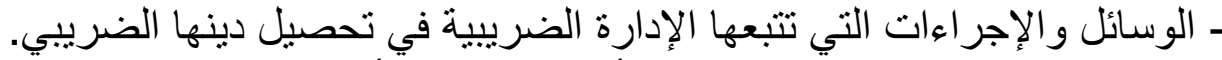

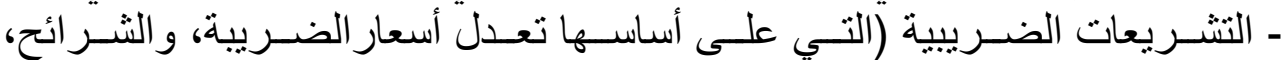

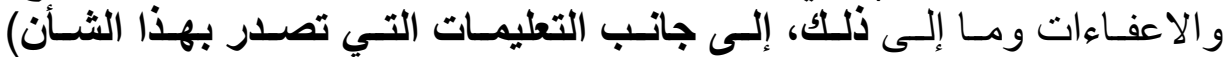

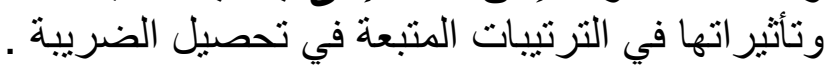

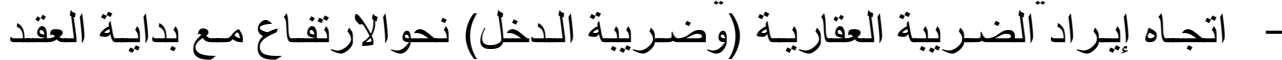

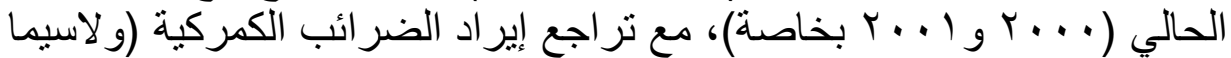

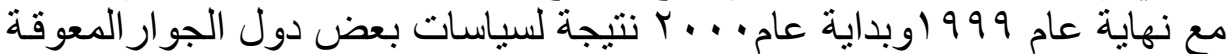

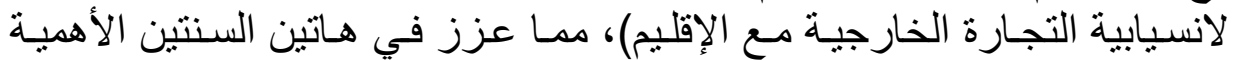

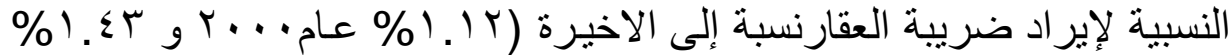

ثانيلَّ" - موقع إيراد ضريبة العقار بين مصادر الإيرادات العامة

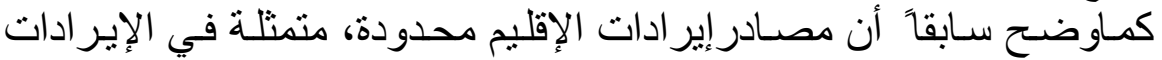

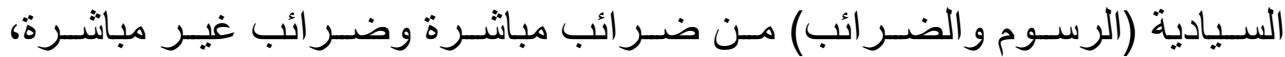

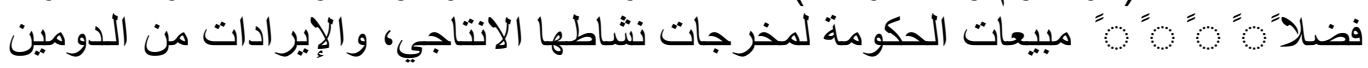

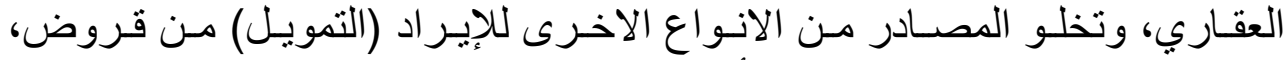

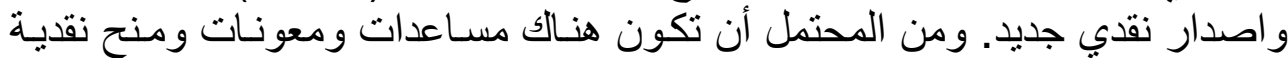

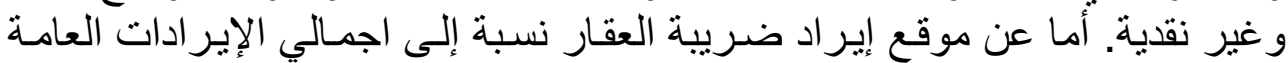

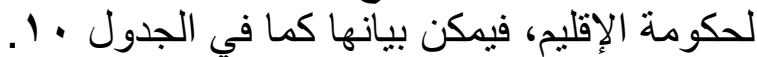

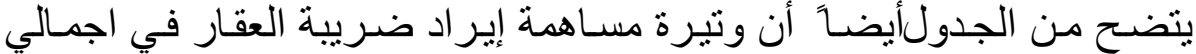

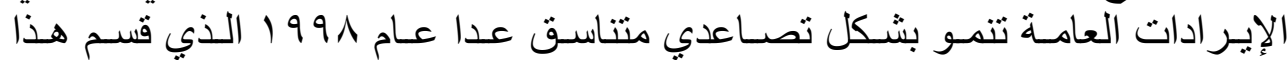

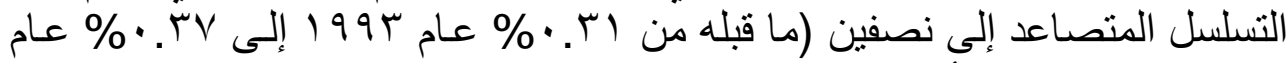

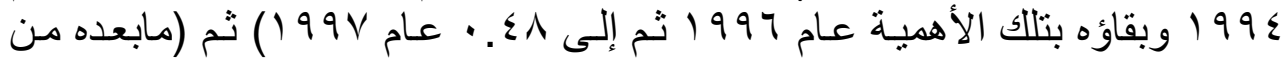

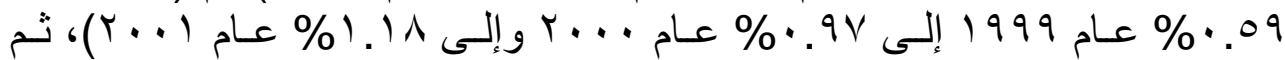

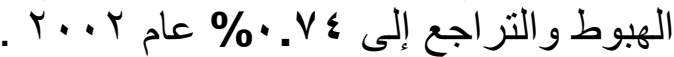

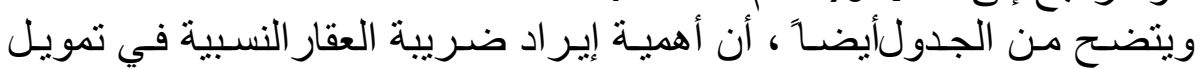

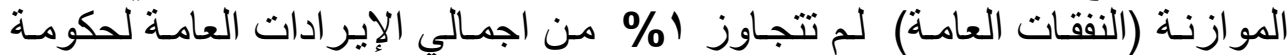

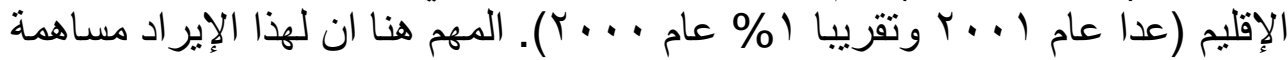

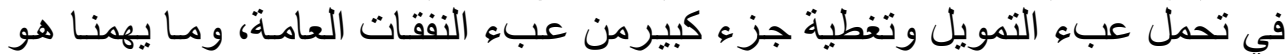

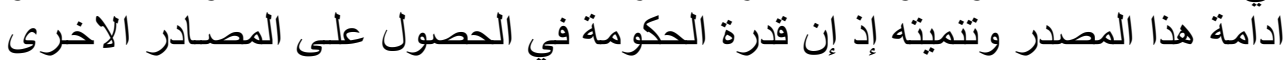

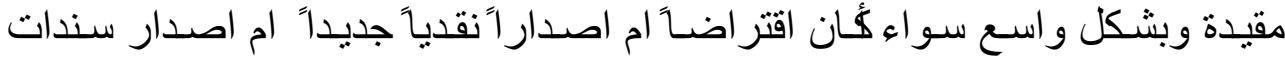

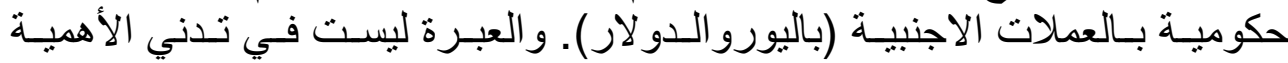


النسبية، اذ إن القيم المطلقة ليست بالمتدنيـة و الضئيلة، ويمكن زيادتها عن طريق والفيق

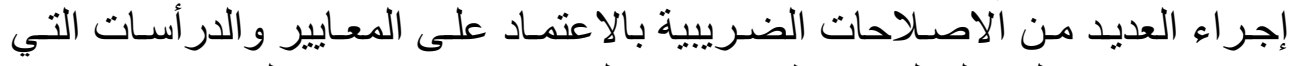

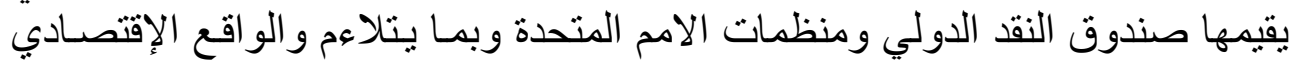
و الإجتماعي و السياسي للإقلقيم (العر اق عامة).

ثالثاً ـ مساهمة إيراد ضريبة العقار في تمويل النفقات العامة

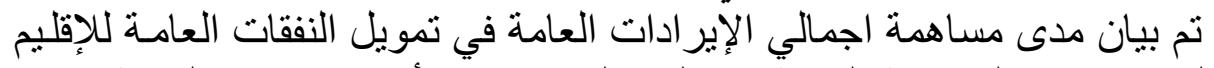

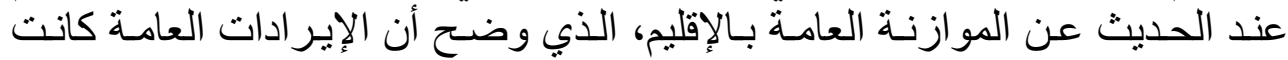

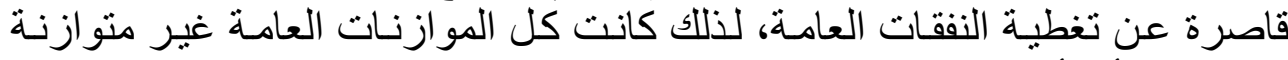

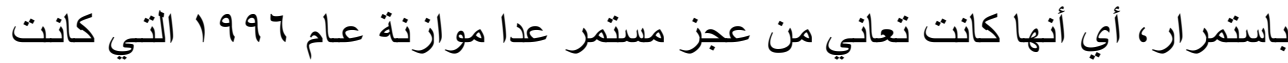

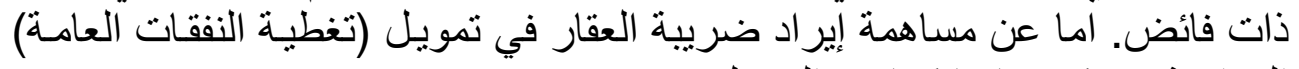

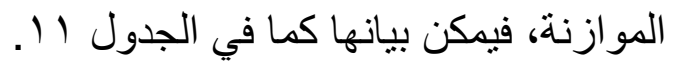

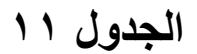

مساهمة إيراد ضريبة العقار في تمويل النفقات العامة لإقليم كوردستان

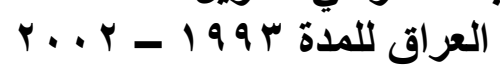

دينار سويسري

\begin{tabular}{|c|c|c|c|}
\hline$\% \quad r: 1$ & r النفقات العامة & إيراد ضريبة العقار & السنة \\
\hline.$Y T$ & 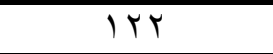 & TIV & 1994 \\
\hline..$Y \wedge$ & 177 & $\{71$ & 1998 \\
\hline.$V Y$ & TE & $r \leqslant q$ & 1997 \\
\hline.$T_{0}$ & TrO & Vqr & 1998 \\
\hline.$Y$. & $r \cdot V$ & 7.1 & 1991 \\
\hline$\therefore \leqslant 0$ & 490 & (1TM & 1999 \\
\hline$\because V$ & 119 & 104 & $r \ldots$ \\
\hline$\because \wedge$. & TYT & IVV & $r \ldots l$ \\
\hline .04 & roo & $1 T \varepsilon$ & $r \ldots r$ \\
\hline
\end{tabular}


يبين الجدول أن مساهمة إير اد ضريبة العقار في تغطية النفقات العامـة (تمويل إلماتل

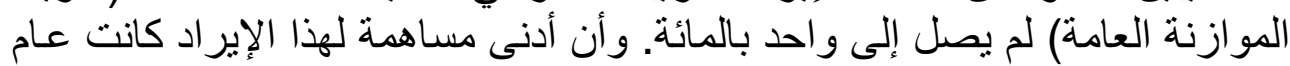

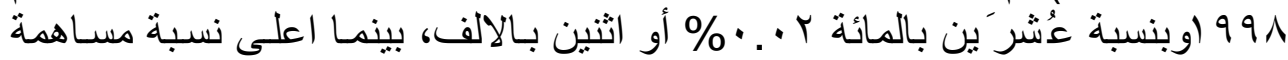

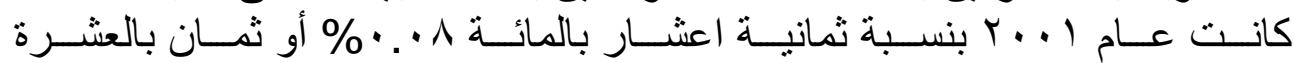

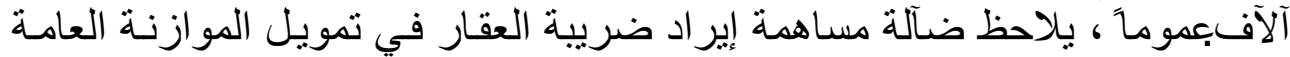

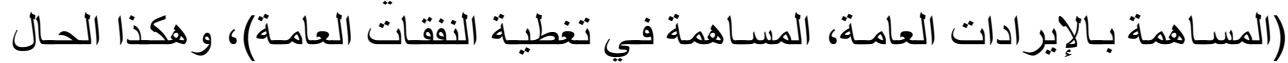

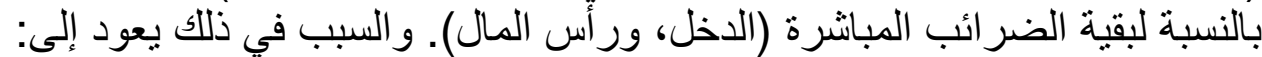

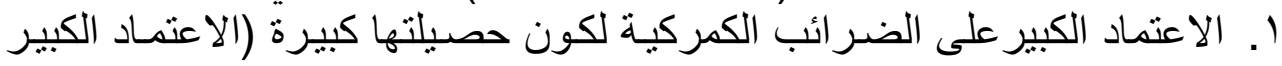

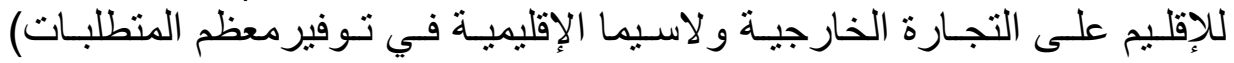

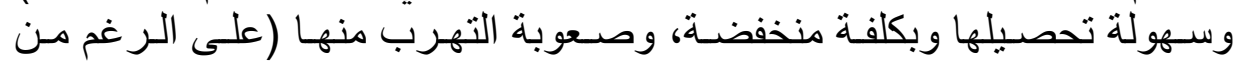

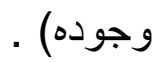

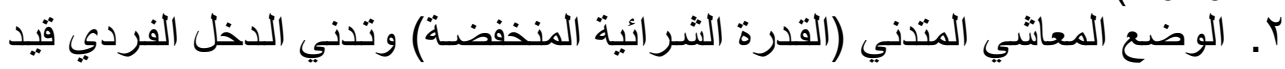

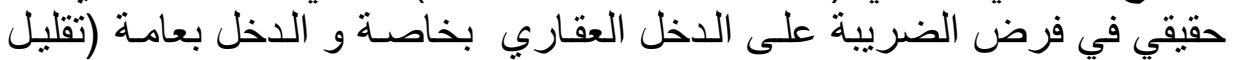

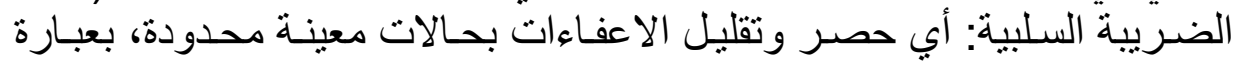

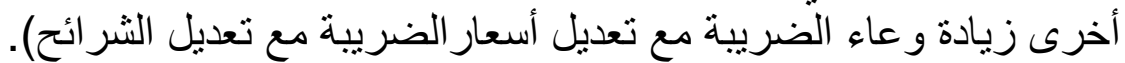

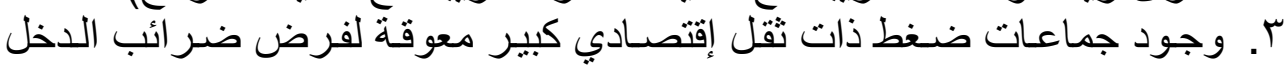

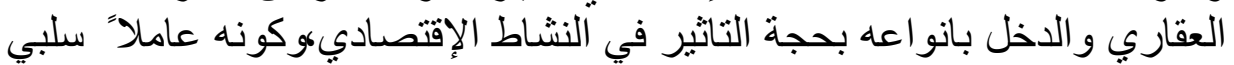
التحفيز. ع. اتباع جماعات الضغط ودافعي الضر ائب الكبيرة للمنافذ القانونية (مثل المادة التي

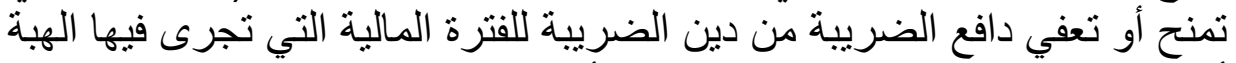

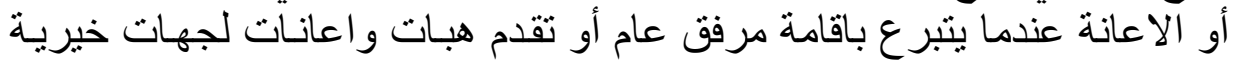

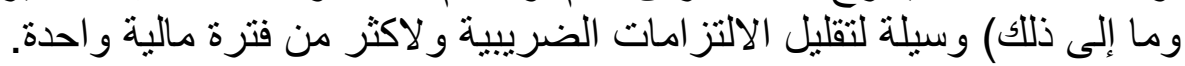

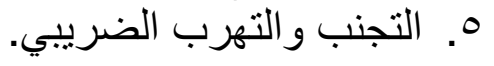

الاستنتاجات

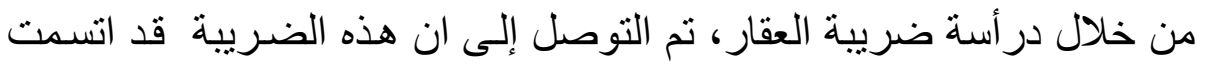

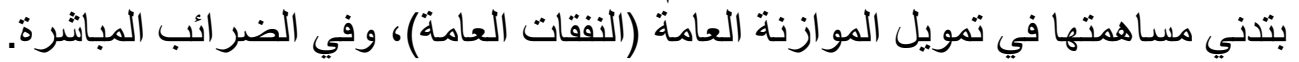

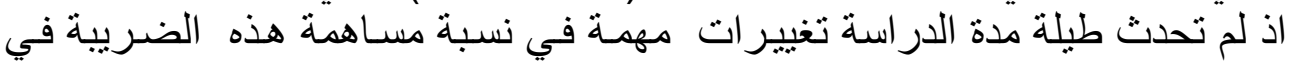

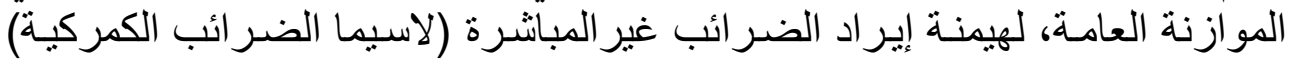

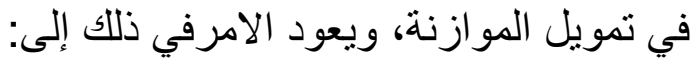

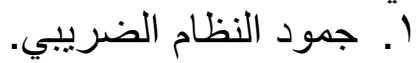

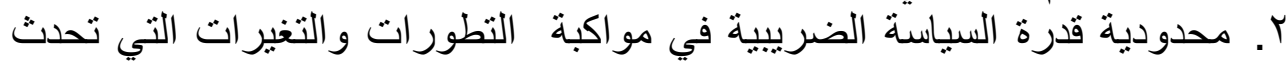

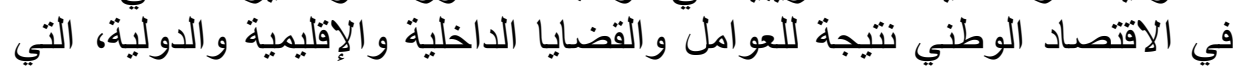

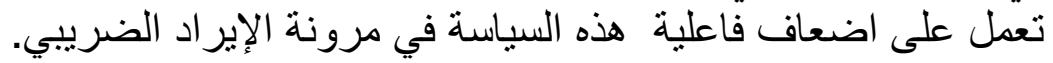
r. تدني كفاءة الإدارة الضريبية ويعود ذللك إلى: 


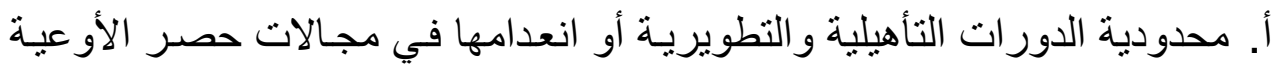

الضريبية و التقدير و التحصيل و غير ها من العمليات المطلوبة لجباية الضريبة.

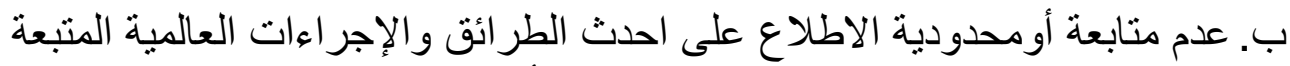
في تحديد الوعاء وفي التقدير الثخصي أو الذاتي، وفي فردية فرض الضئ الضريبة

وجبايتها.

ج. محدودية استخدام الوسائل التقنية الحديثة والمتطورة من حواسيب الكترونية (تستخدم دوليا على نطاق واسع في مجالات التقدير، ومن شنبكة التبة المعلوماتية

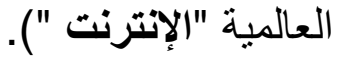

المقترحات

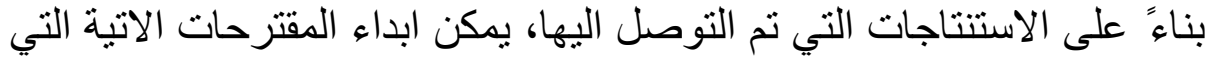

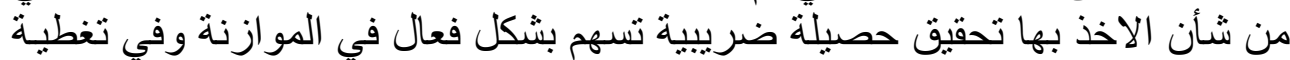

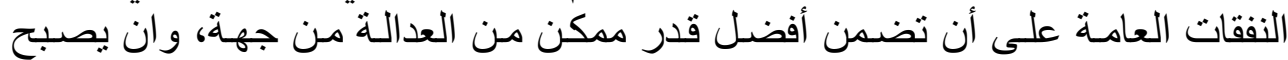

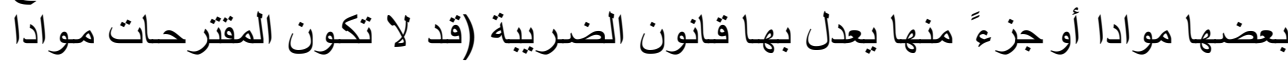

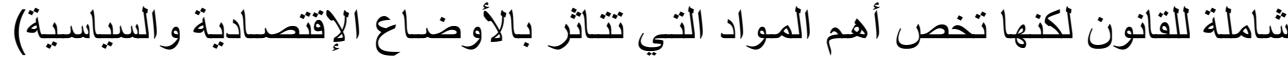

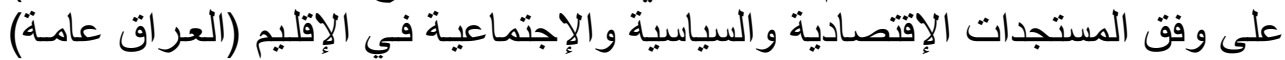

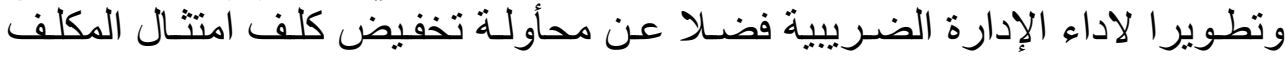

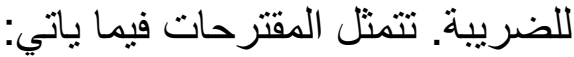

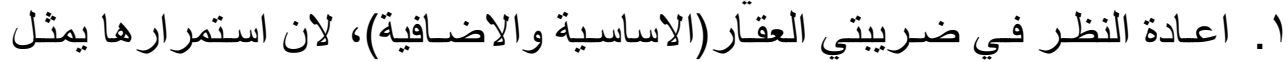

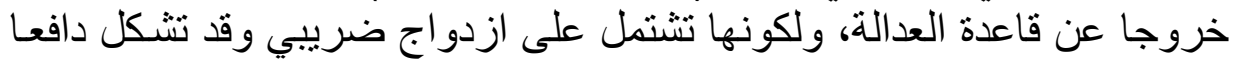

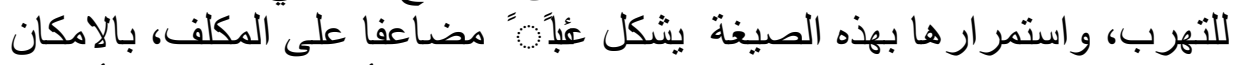

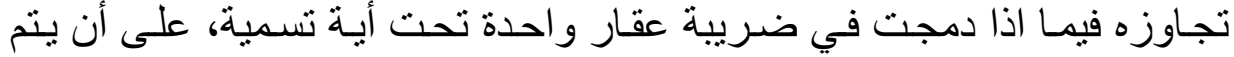

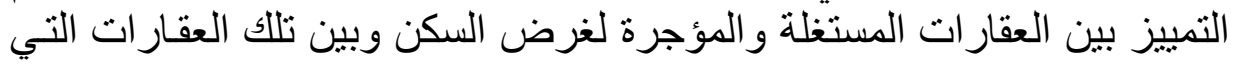

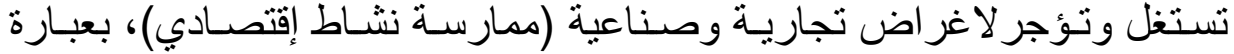

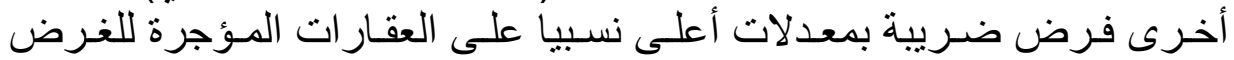

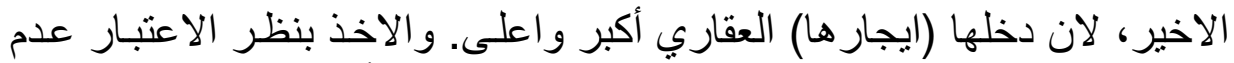

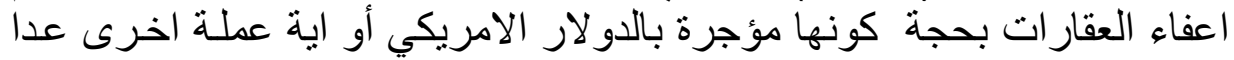

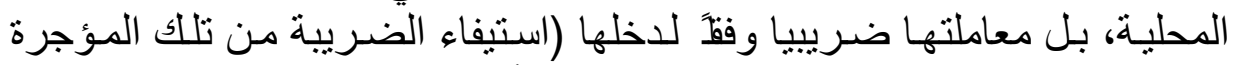

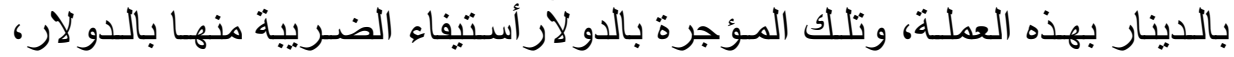

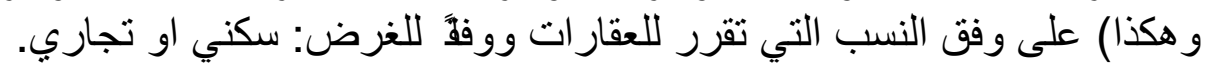

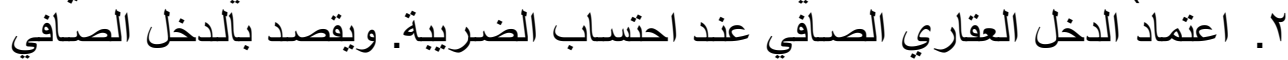

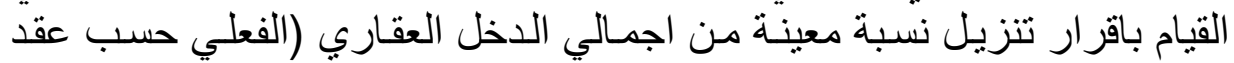

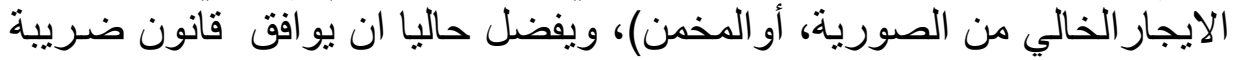

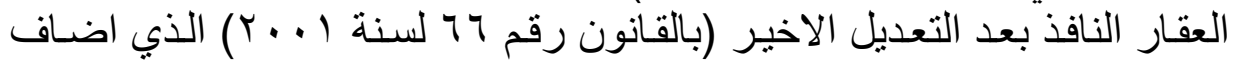

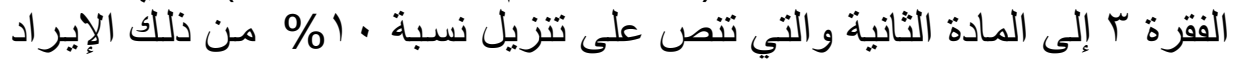

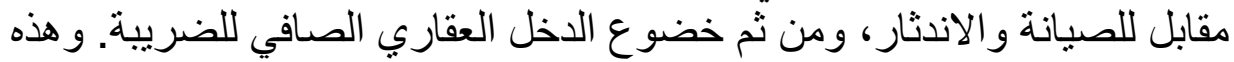


النقة امتداد لتطبيق القانون الذي ينص على إقليمية الضريبة (امتلاك المكلف

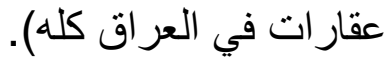

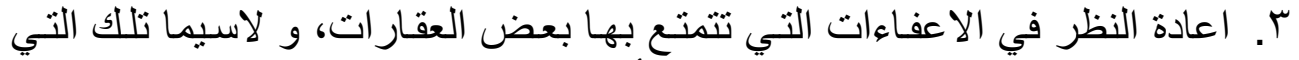

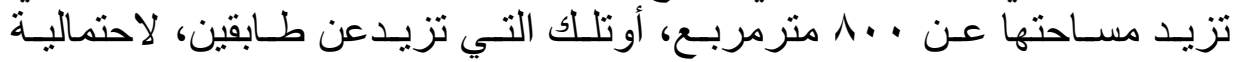

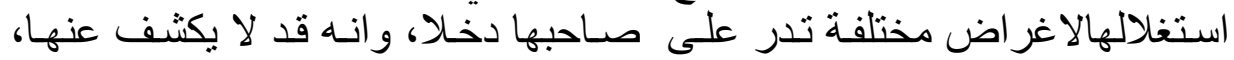
وتخرج عن نطاق خضو عها للضريبة الضانية.

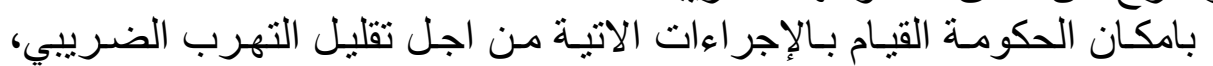
فضلا عن معالجة ظاهرة الفساد في إدارة الضريبة (إن وجدات الاتة):

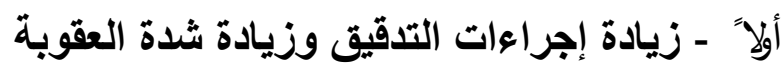

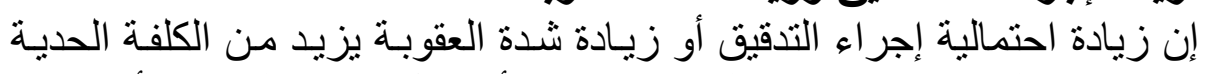

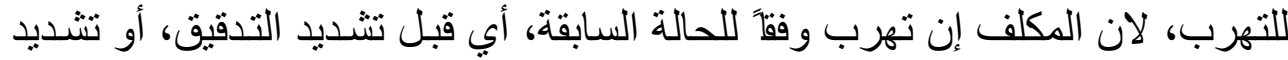

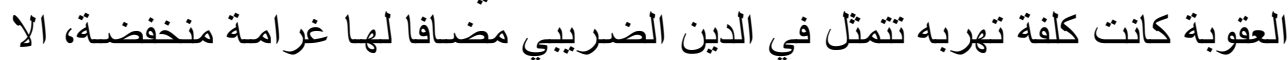

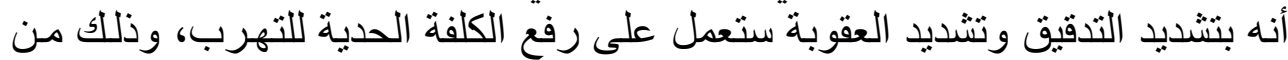

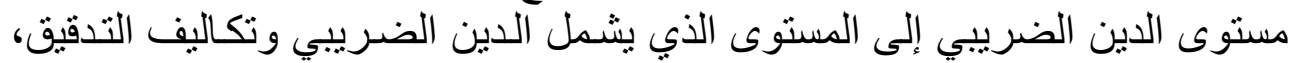

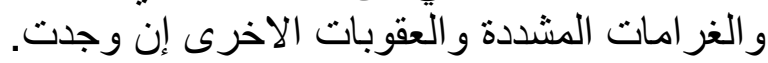

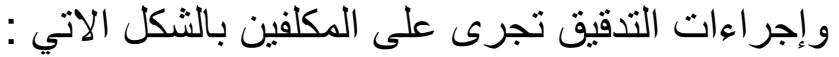

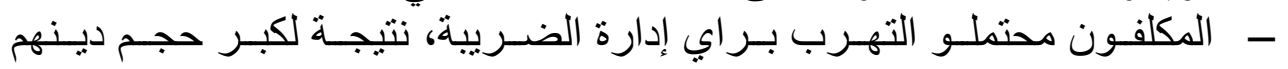
- الضريبي. - الذكلفون الذين سبق وأن تهربوا.

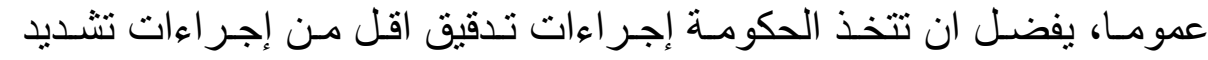

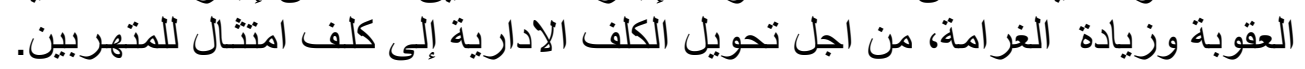

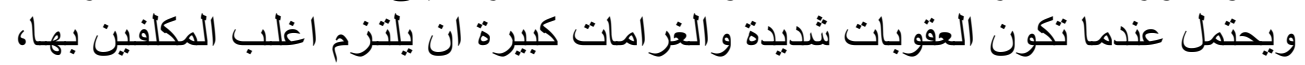

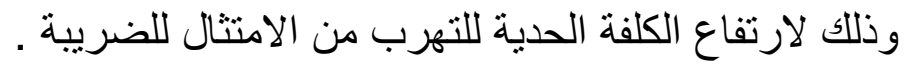

$$
\text { ثانياً ـ السياسات المشجعة للامتثال الضريبي }
$$

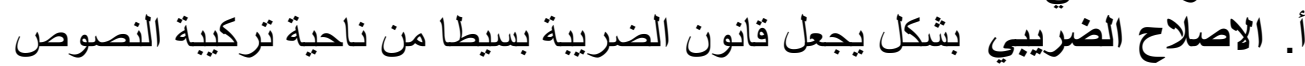

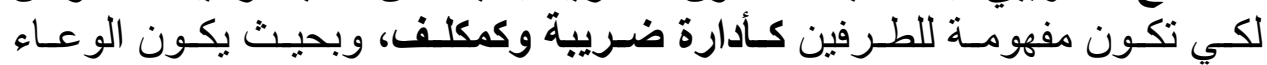

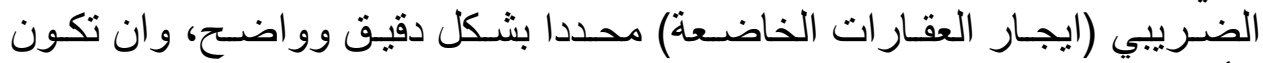

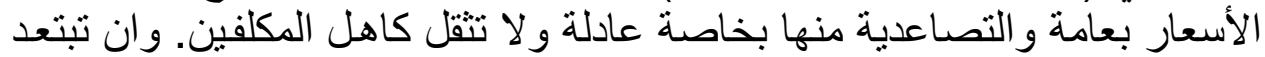

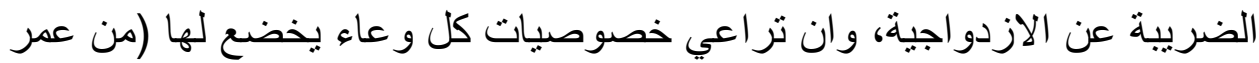

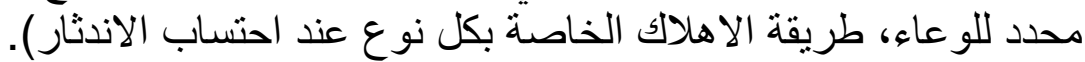

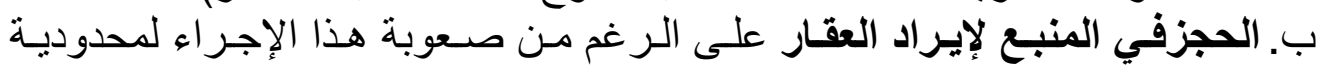

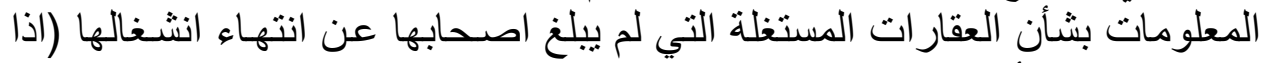
كانت شاغرة)، أو انه قد استغل اذا كان العقار حديث التشييد، و غير ها. 


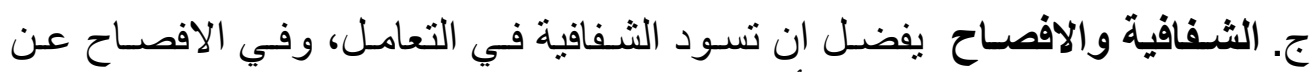

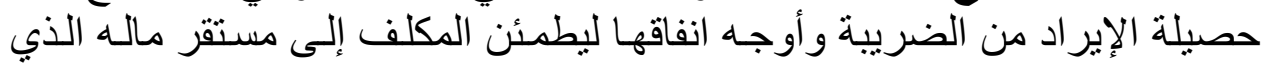

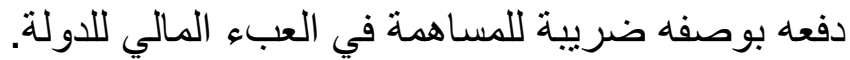

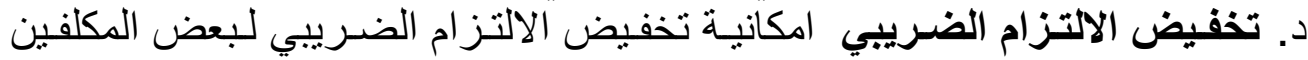

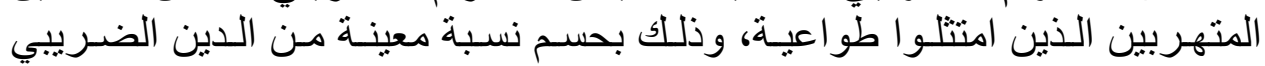

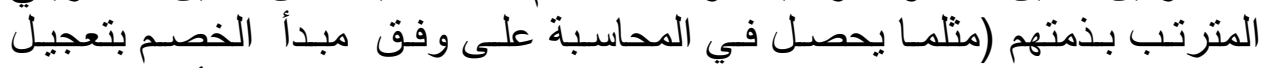

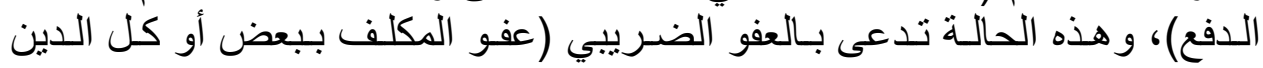
الضريبي بعد فرض الضره الضريبة عليه).

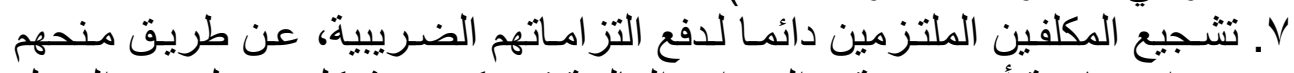

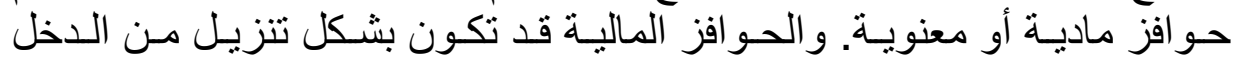

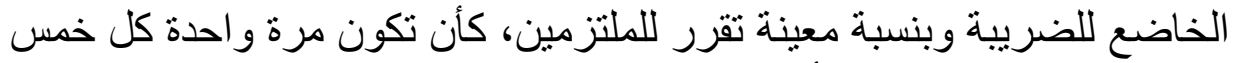

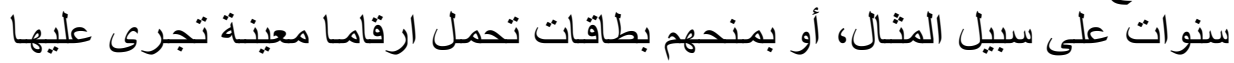

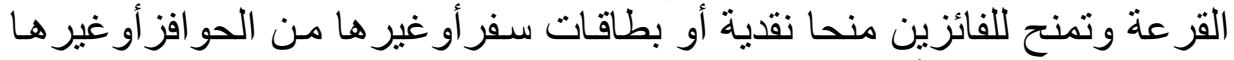

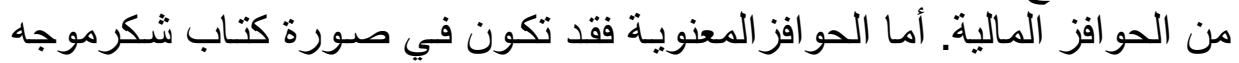

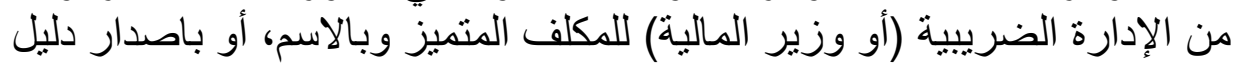

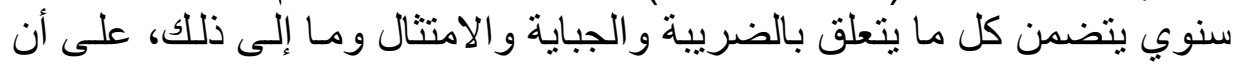

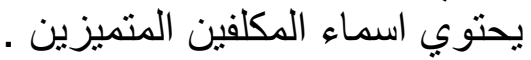

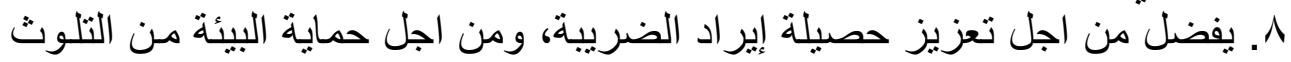

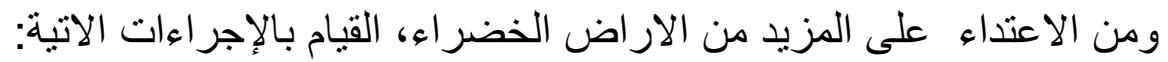

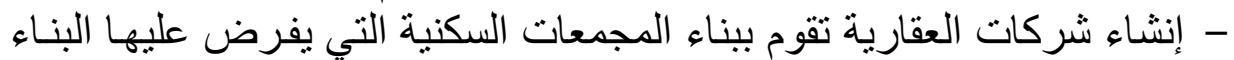

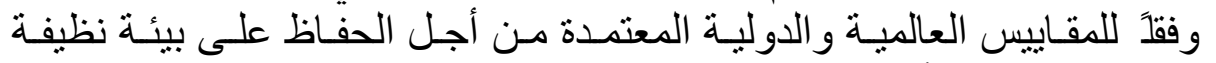

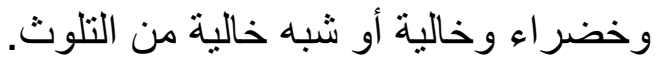

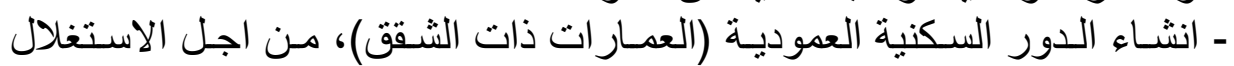

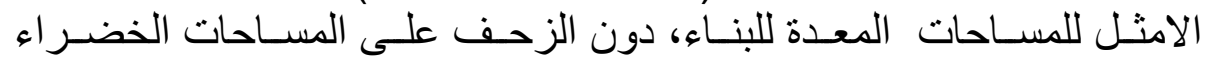

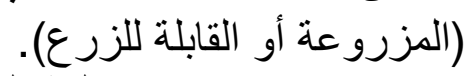

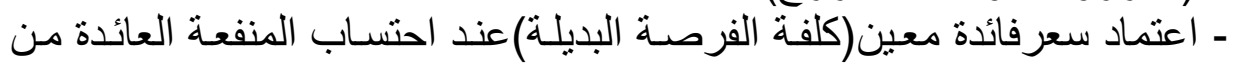

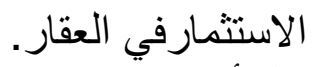

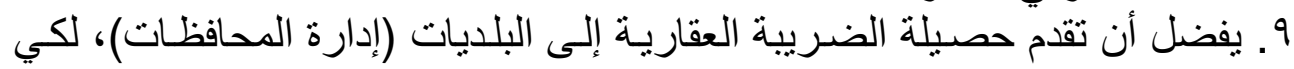

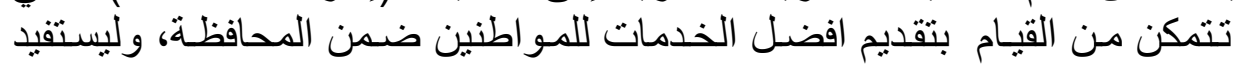

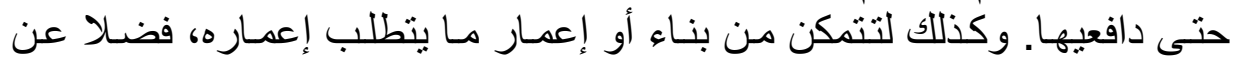

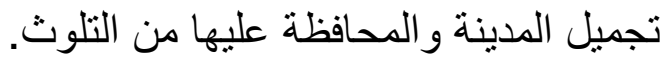

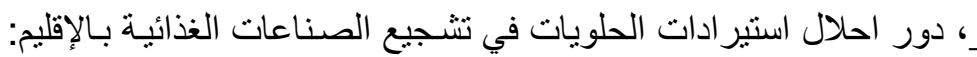

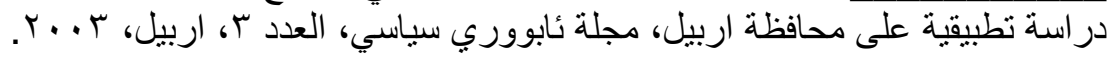

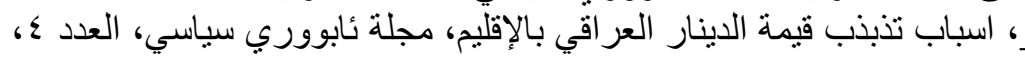

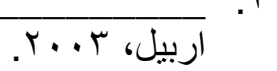

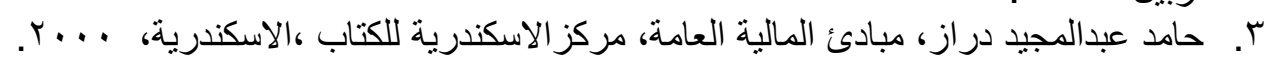


ع. ـ حكومة إقليم كوردستان العراق، وزارة المالية والاقتصـاد، الموازنات السنوية: غيرمنشورة،

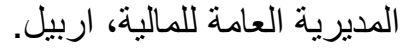

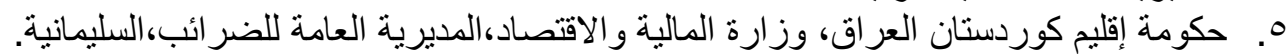

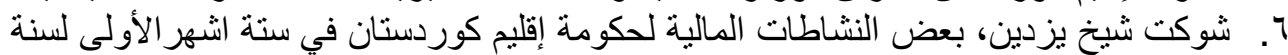

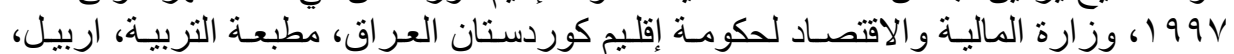

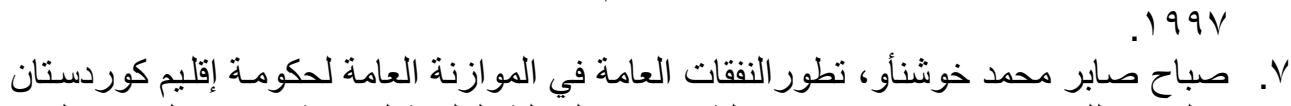

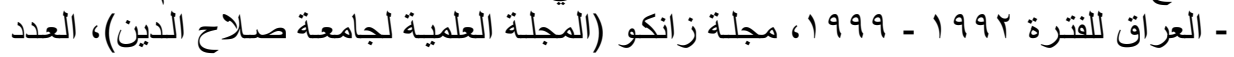

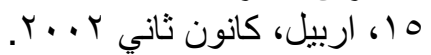

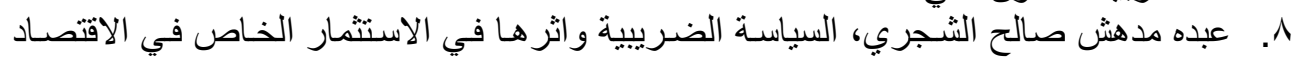

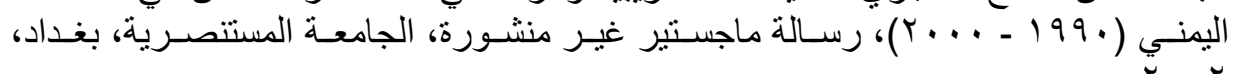
r...r

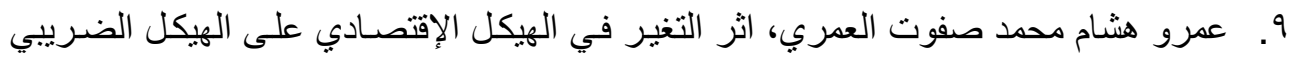

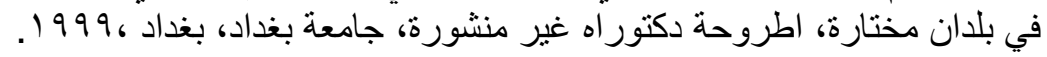

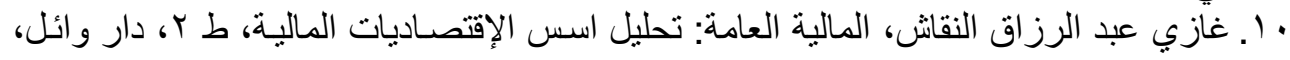

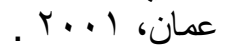

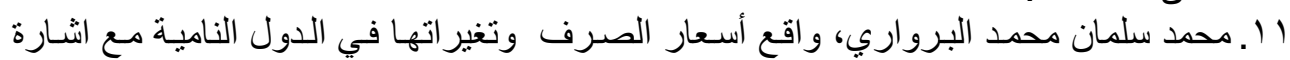

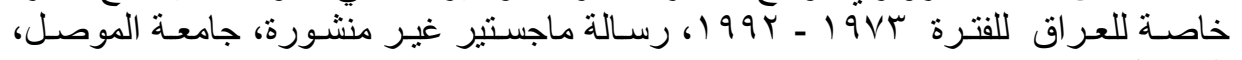

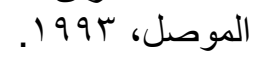

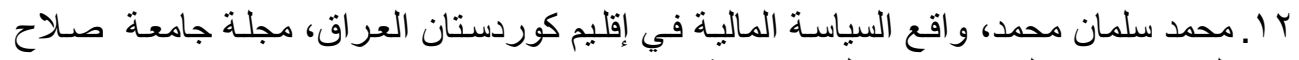

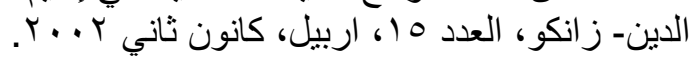

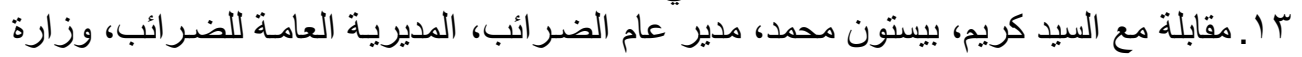

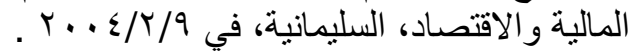

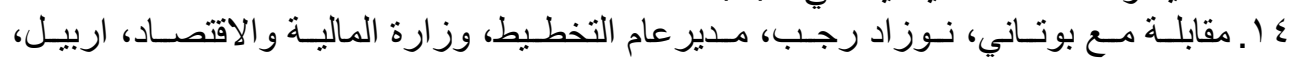
$r . r / r / 9$

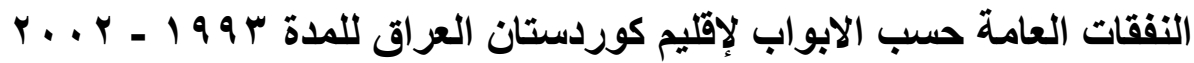

\section{الف دينار سويسري}

$\mathrm{x}$ 


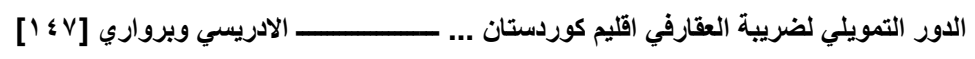

المصدر: حكومة إقليم كوردستان العراق، وزارة المالية، المديرية العامة للإيرادات، قسم الميزانية،

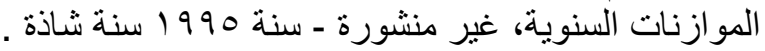

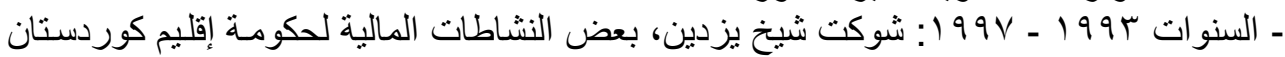

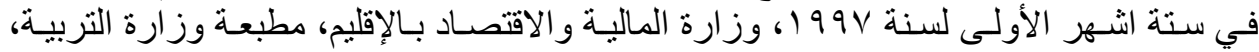

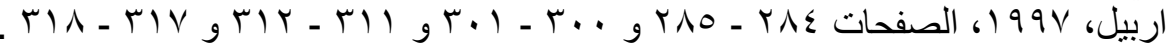

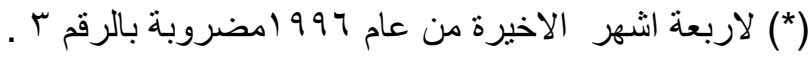

